\title{
Carving out a new role: the UIA after the Second World War
}

Citation for published version (APA):

Randeraad, N., \& Post, P. (2019). Carving out a new role: the UIA after the Second World War. In D. Laqua, W. Van Acker, \& C. Verbruggen (Eds.), International Organizations and Global Civil Society: Histories of the Union of International Associations (pp. 73-90). Bloomsbury Academic.

https://doi.org/10.5040/9781350055643.0013

Document status and date:

Published: 04/04/2019

DOI:

10.5040/9781350055643.0013

Document Version:

Publisher's PDF, also known as Version of record

Document license:

Taverne

Please check the document version of this publication:

- A submitted manuscript is the version of the article upon submission and before peer-review. There can be important differences between the submitted version and the official published version of record.

People interested in the research are advised to contact the author for the final version of the publication, or visit the DOI to the publisher's website.

- The final author version and the galley proof are versions of the publication after peer review.

- The final published version features the final layout of the paper including the volume, issue and page numbers.

Link to publication

\footnotetext{
General rights rights.

- You may freely distribute the URL identifying the publication in the public portal. please follow below link for the End User Agreement:

www.umlib.nl/taverne-license

Take down policy

If you believe that this document breaches copyright please contact us at:

repository@maastrichtuniversity.nl

providing details and we will investigate your claim.
}

Copyright and moral rights for the publications made accessible in the public portal are retained by the authors and/or other copyright owners and it is a condition of accessing publications that users recognise and abide by the legal requirements associated with these

- Users may download and print one copy of any publication from the public portal for the purpose of private study or research.

- You may not further distribute the material or use it for any profit-making activity or commercial gain

If the publication is distributed under the terms of Article $25 \mathrm{fa}$ of the Dutch Copyright Act, indicated by the "Taverne" license above, 


\title{
Chapter 4
}

\section{CARVING OUT A NEW ROLE: THE UIA AFTER THE SECOND WORLD WAR}

\author{
Nico Randeraad and Philip Post
}

After the death of its founders Henri La Fontaine in 1943 and Paul Otlet in 1944, it was uncertain whether the Union of International Associations would be able to resume its activities once the Second World War had ended. The only concrete step was the installation of Otlet's lawyer, Jules Polain, as provisional administrator in May 1945. La Fontaine's bequest provided funds to relaunch the Union, but there was no apparent urgency to spend the money. On the contrary, the court order appointing Polain contained the possibility of a total liquidation of the organization. ${ }^{1}$

The tide turned in the spring of 1948, after the Economic and Social Council of the United Nations (ECOSOC) commissioned UN official Lyman C. White to promote the participation of non-governmental organizations (NGOs). As part of his activities, White paid a visit to Brussels, where he sought to convince Polain and his associates that the Union could occupy a special place in the new global order of international organizations. He urged them to launch a new international journal and suggested that financial support from the United States might be available. Within a few months, the Union was brimming with initiatives. Four hundred questionnaires were dispatched to international associations. Georges Patrick Speeckaert was taken on as secretary and sent to America to lobby for the Union. In January 1949, the UIA's first Monthly Bulletin - featuring the recurrent promotional reference: 'founded in 1910' - was published.

It was clear that White's suggestions were taken seriously and greatly helped to revive the UIA. It proved, however, difficult for the Union to integrate effectively into the transnational scene of the post-war years. Whereas in this period, as Akira Iriye argues, transnationalism 'was being fortified with a strong organizational base, the Union struggled to acquire a sound financial basis and to find its place among the growing number of international (non-governmental) organizations. ${ }^{2}$ The central aim of this chapter, therefore, is to find out why the UIA had such difficulties in (re-)establishing itself as a hub of international non-governmental organizations after the Second World War. 


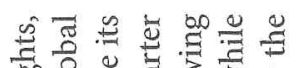

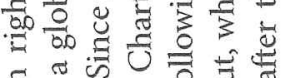

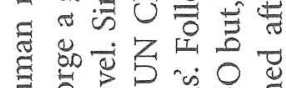
s. ᄋิ \&.

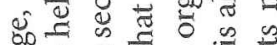

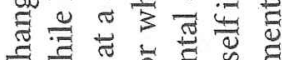
บ

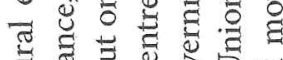

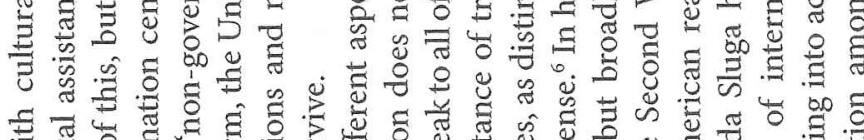

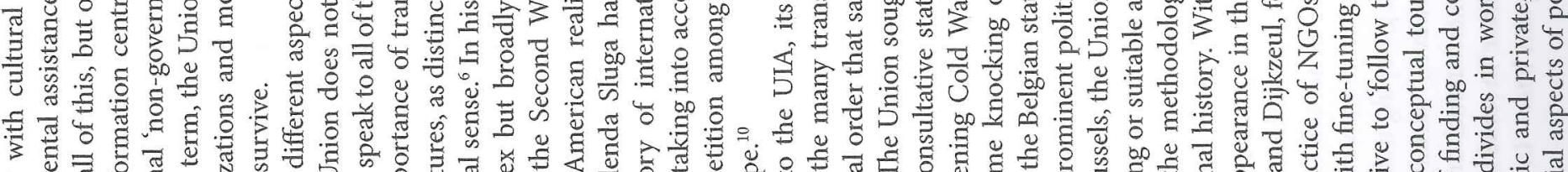

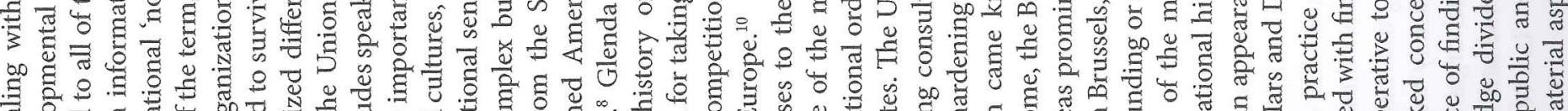

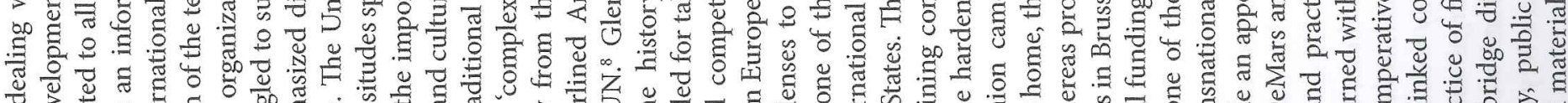

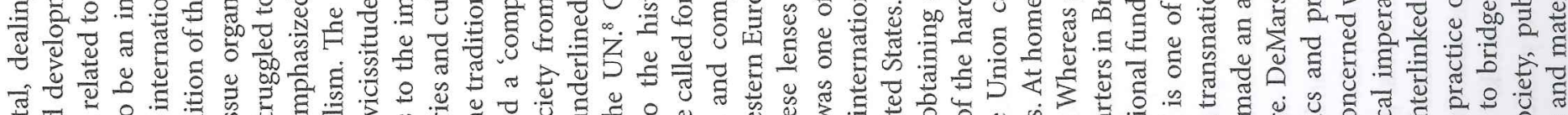

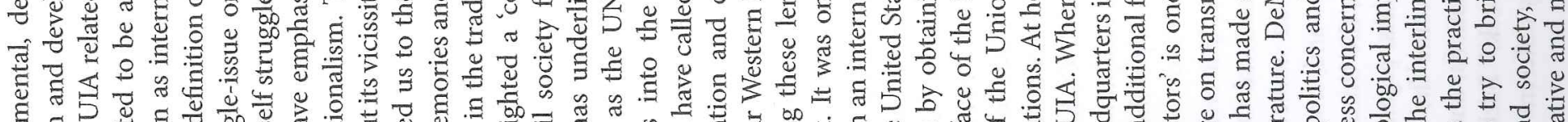

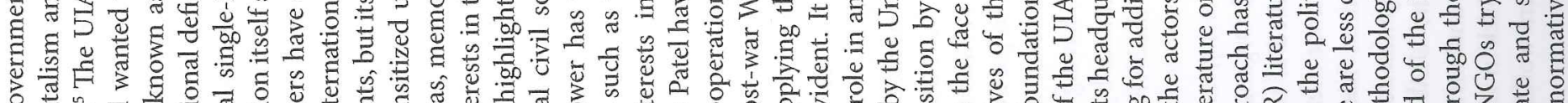

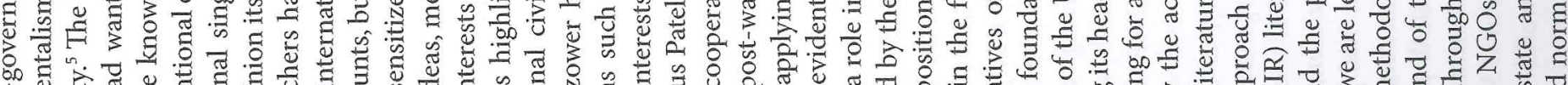

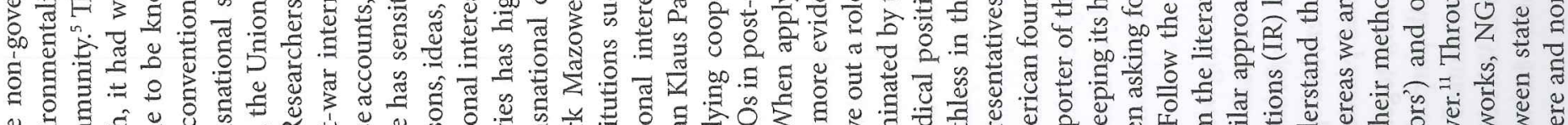

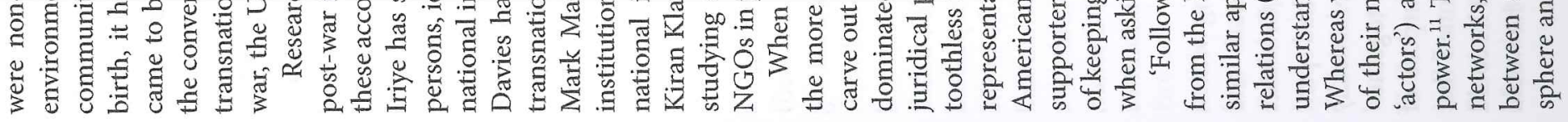

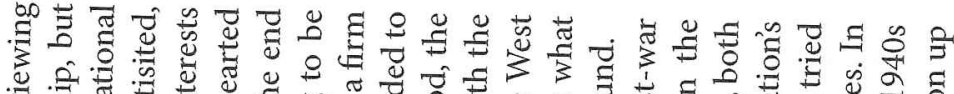

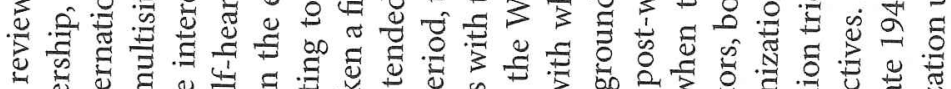

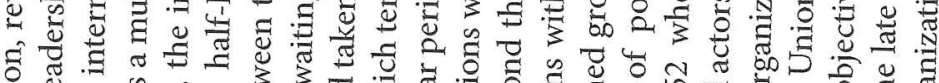

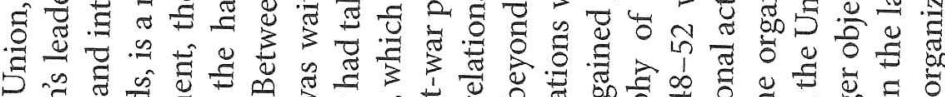
等

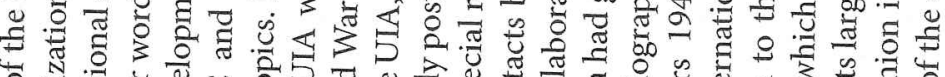

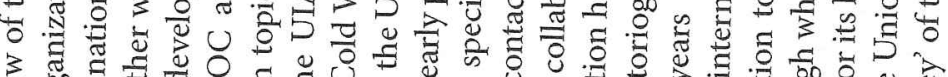

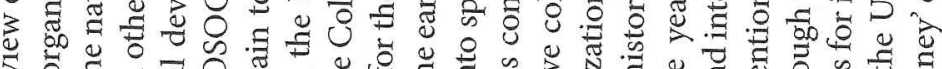

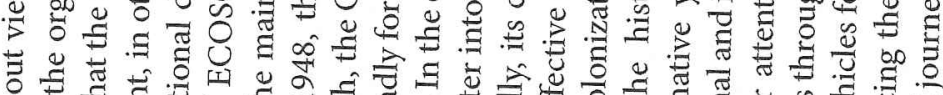

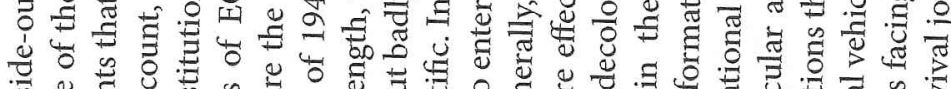

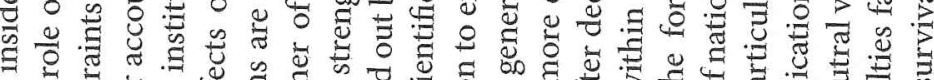

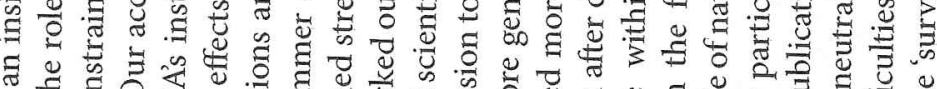

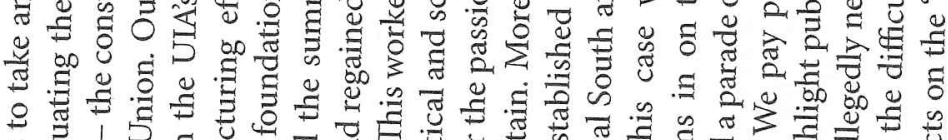
a

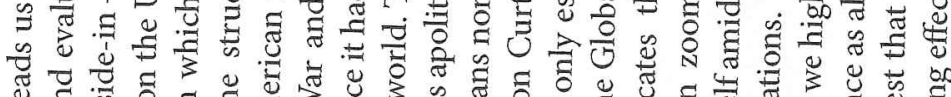

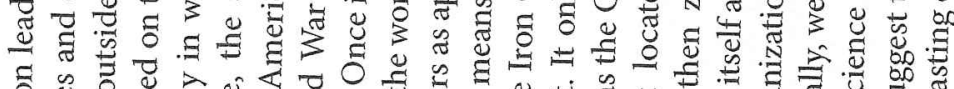

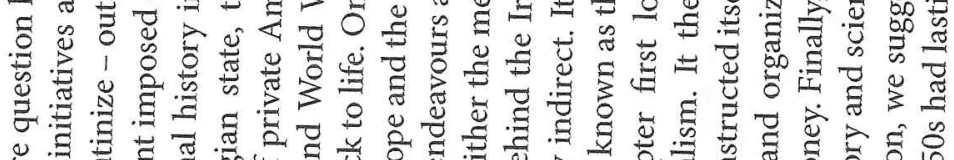

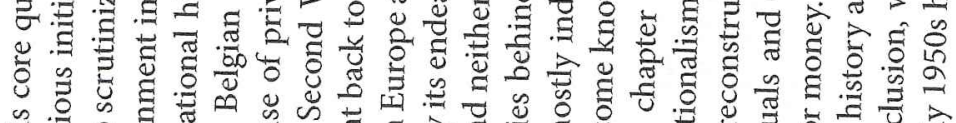

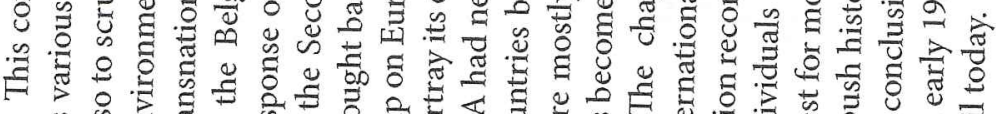

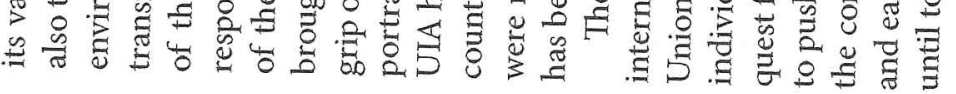

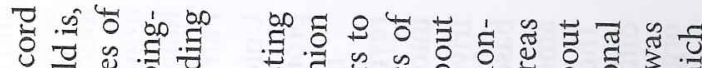

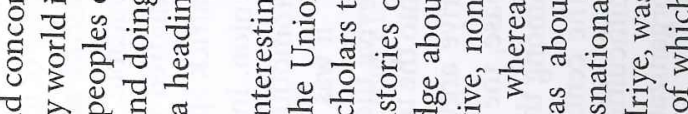

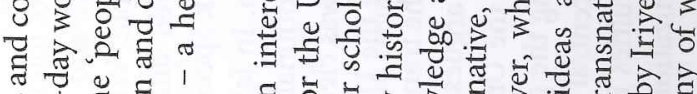

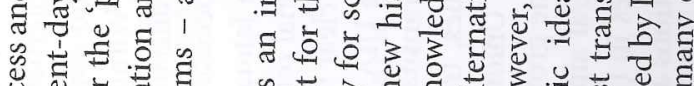

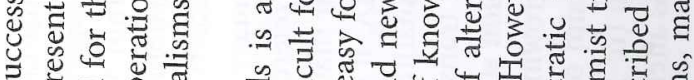

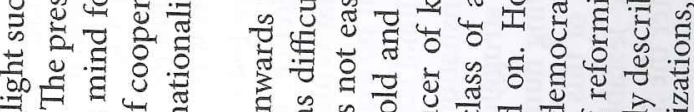

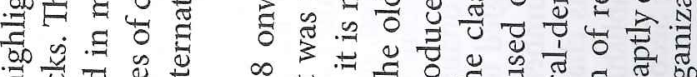

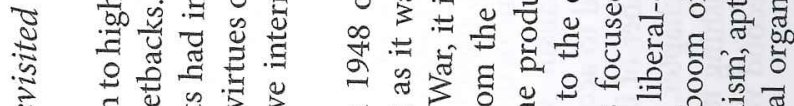

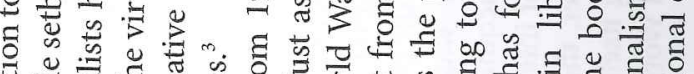

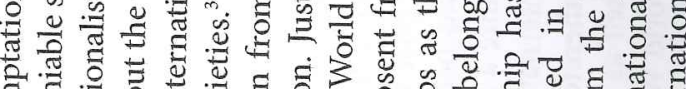
2. 은 흔

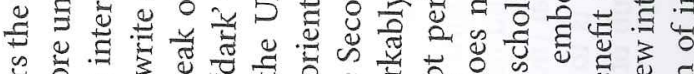

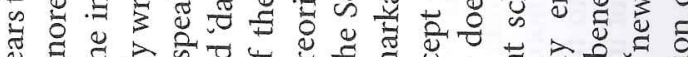

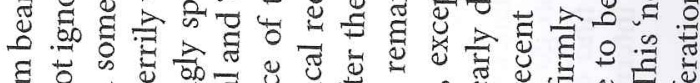
E

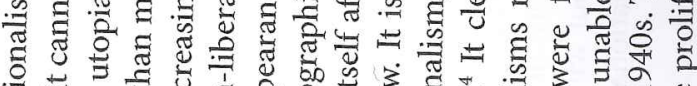

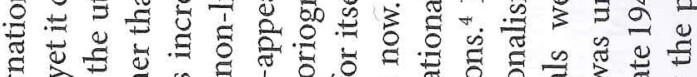

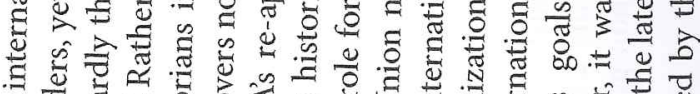

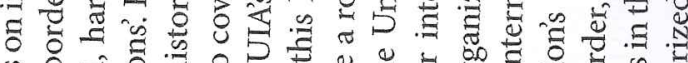

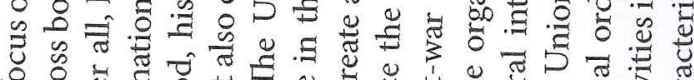

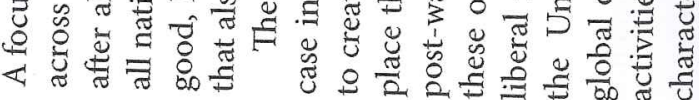




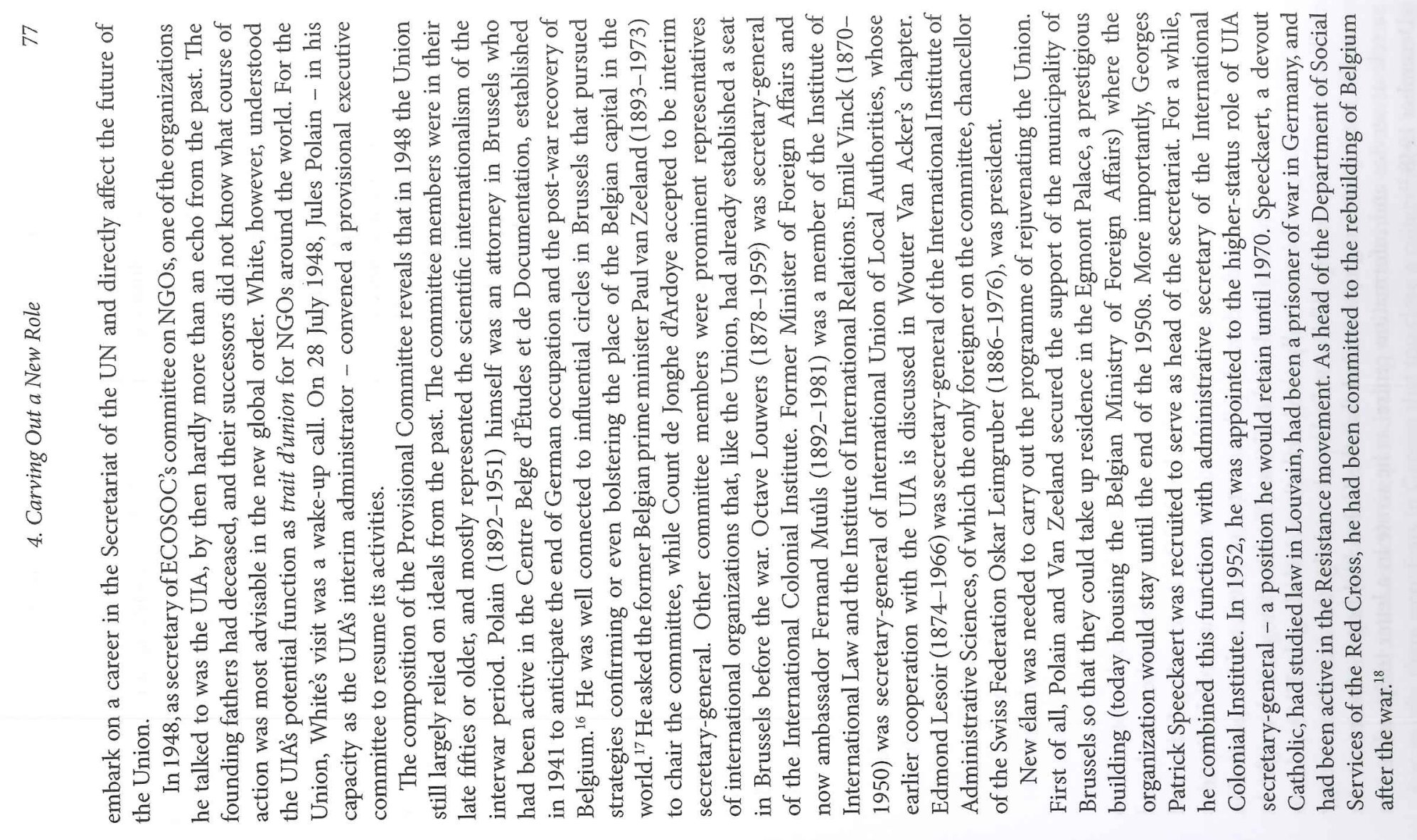

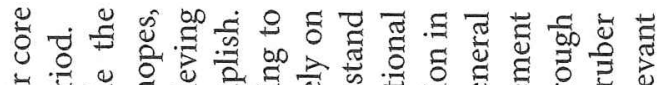

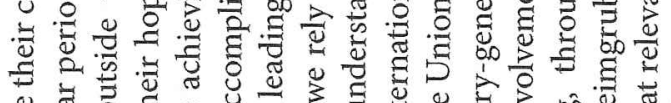

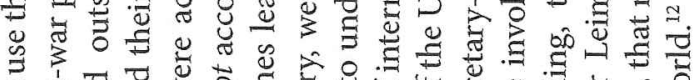

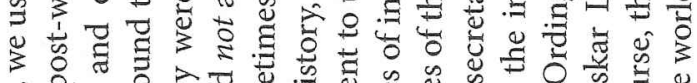
की

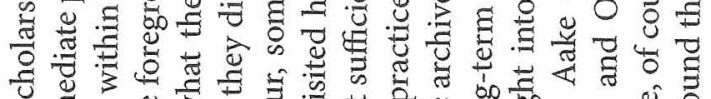

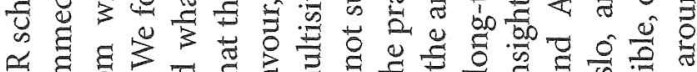

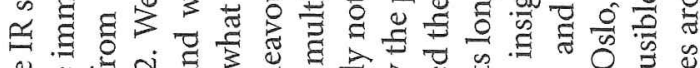

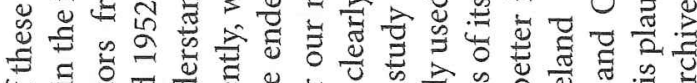

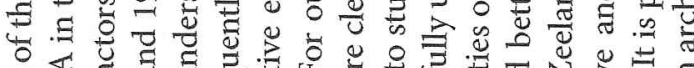

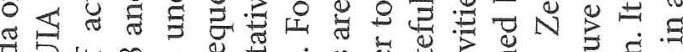

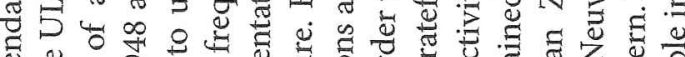

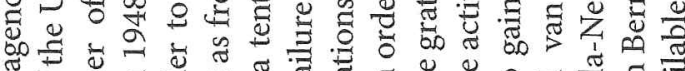

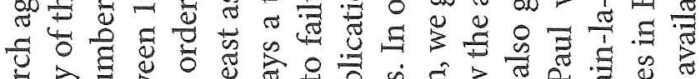

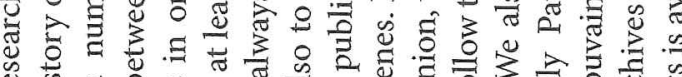

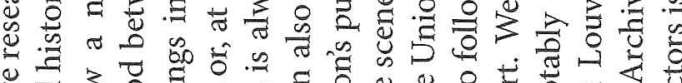

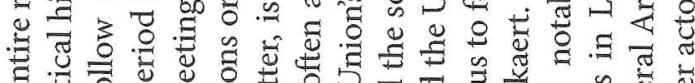

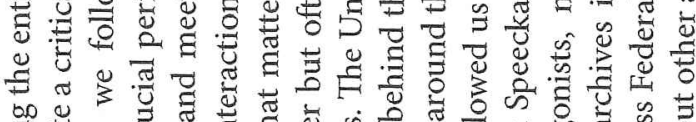
bo:

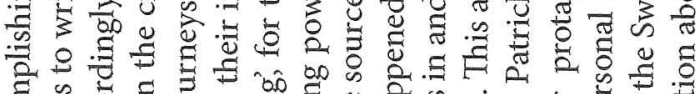
ఫั

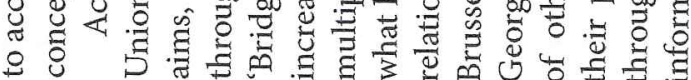

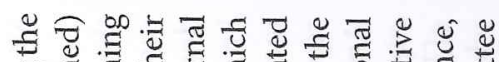

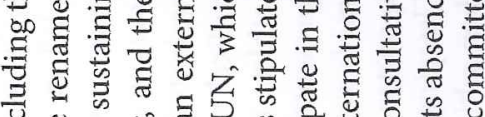

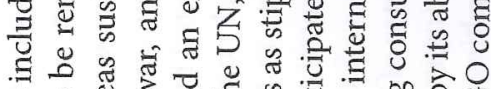

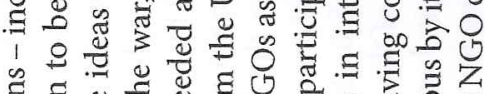

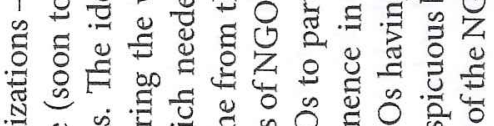

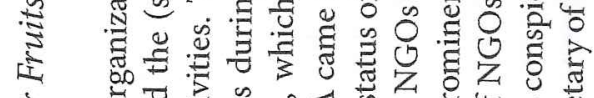

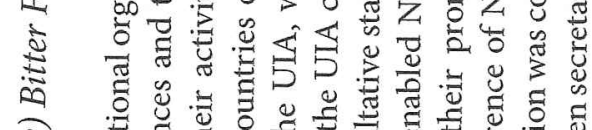

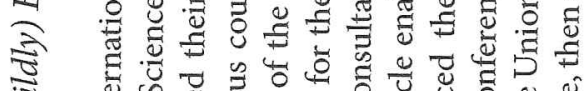

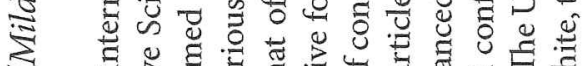
उ

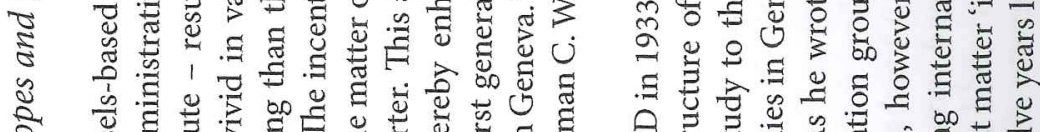

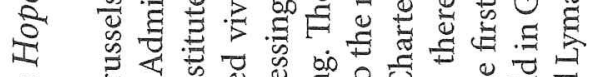

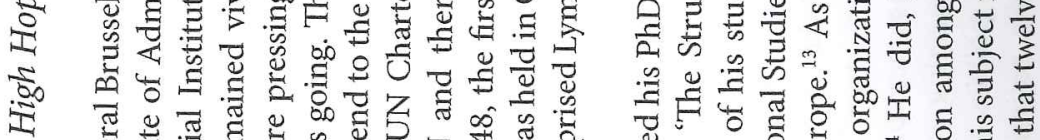

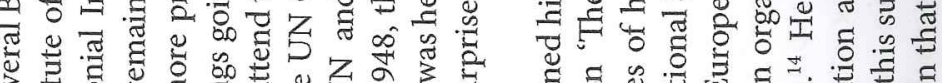

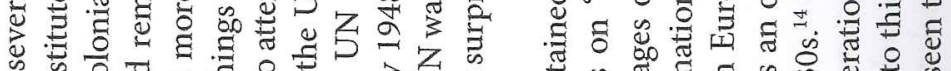
心

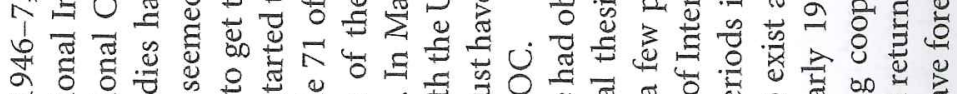

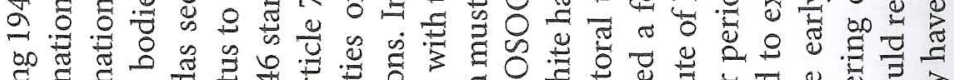

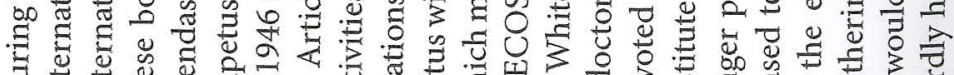

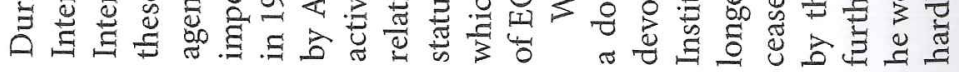




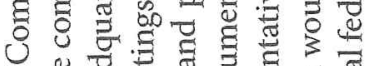

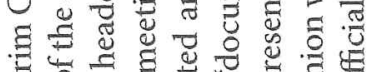

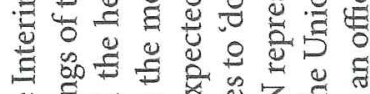

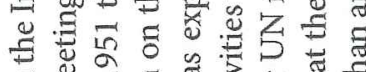

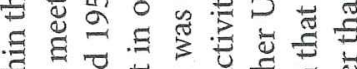

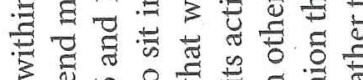

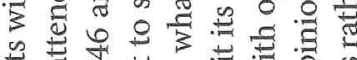

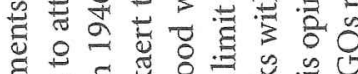

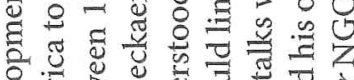

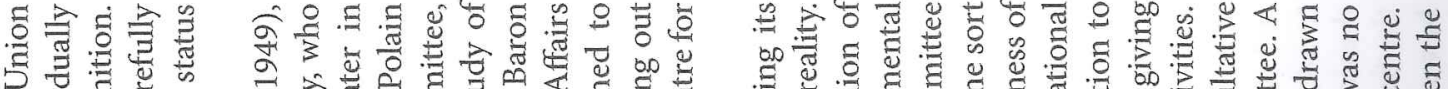
‡

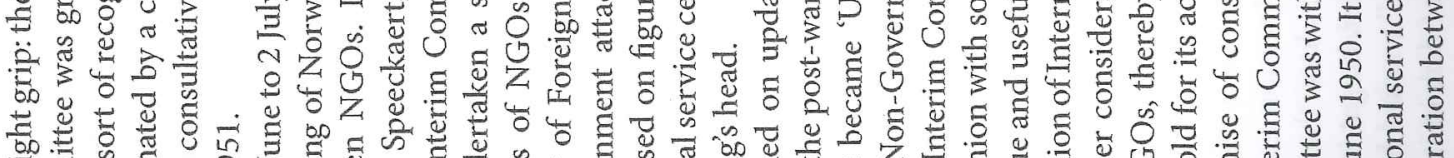

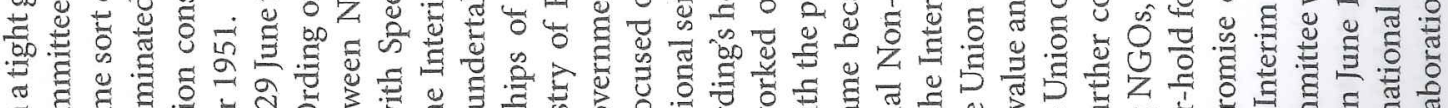

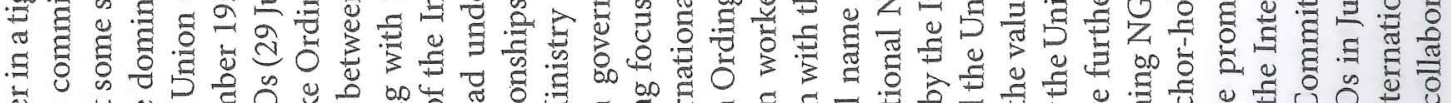

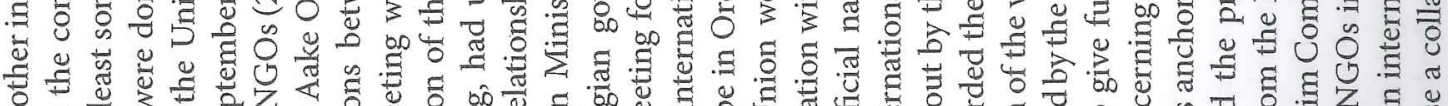

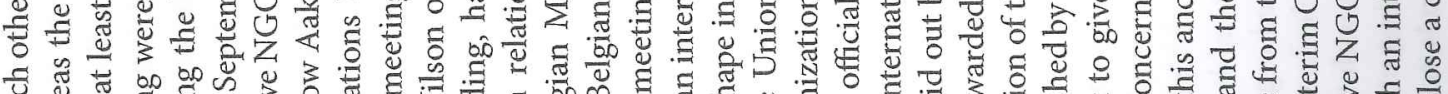

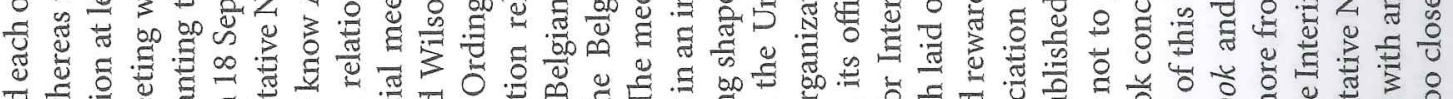

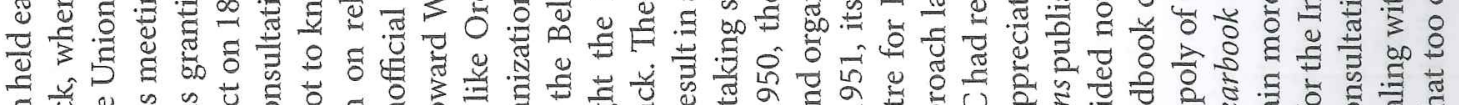

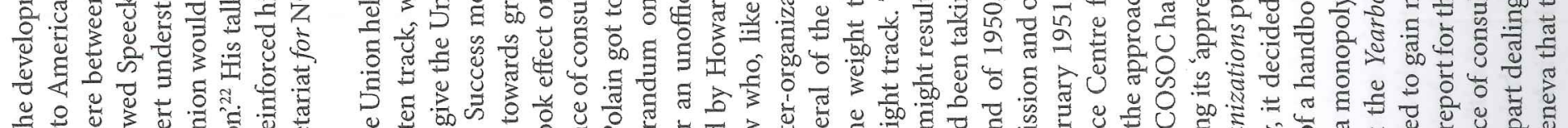

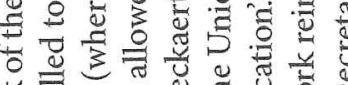

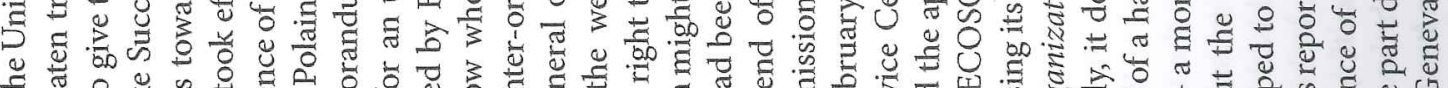

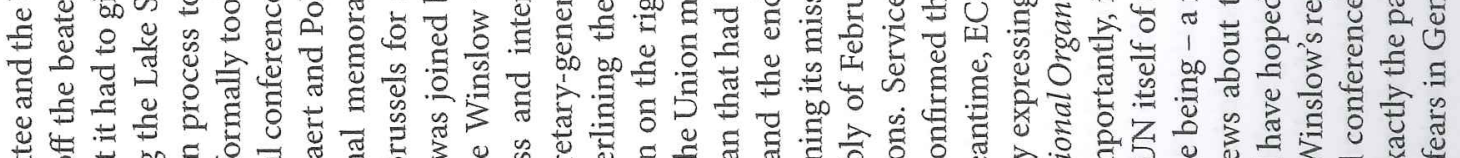

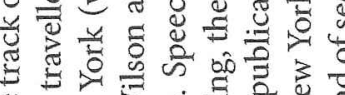

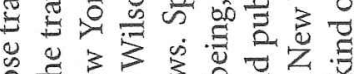

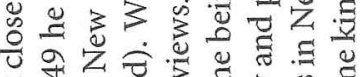

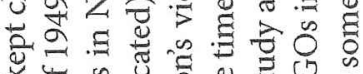

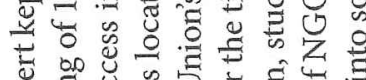

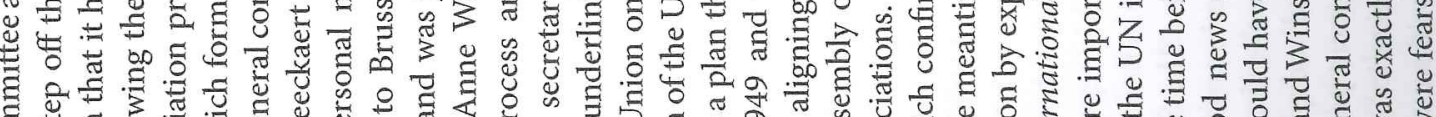

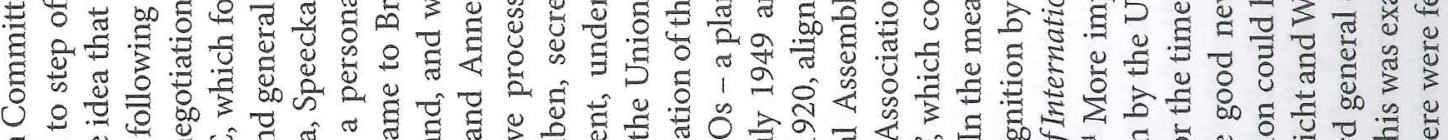

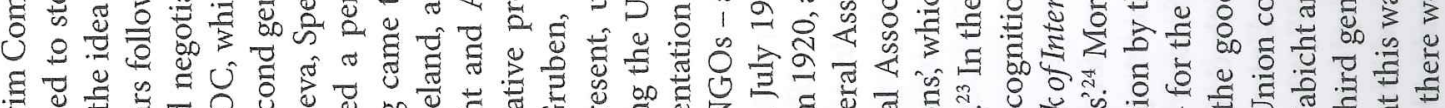

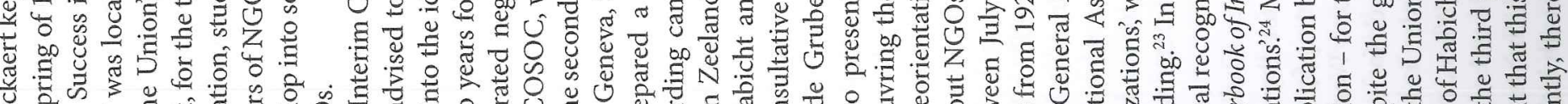

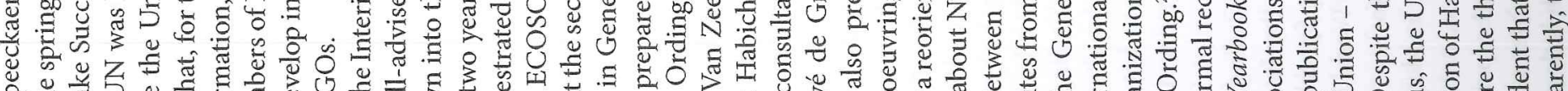

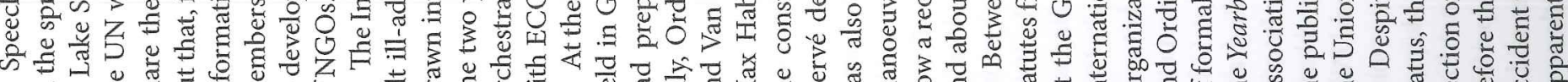

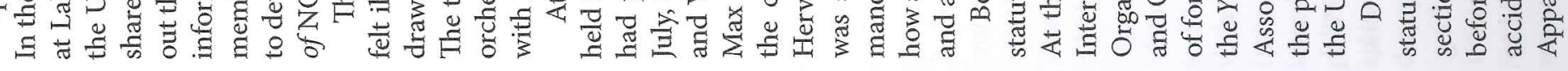

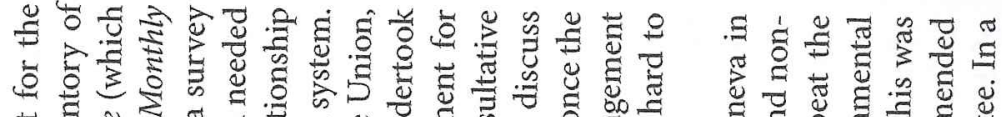

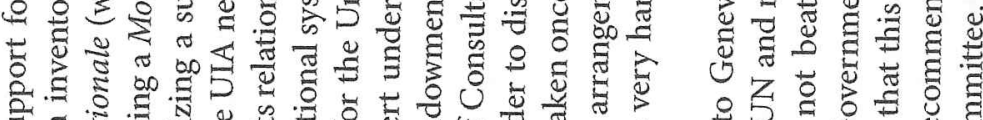

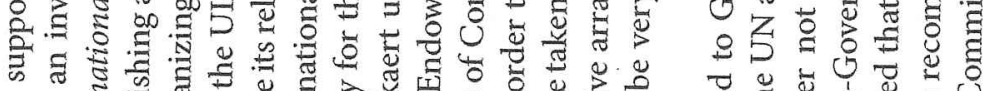

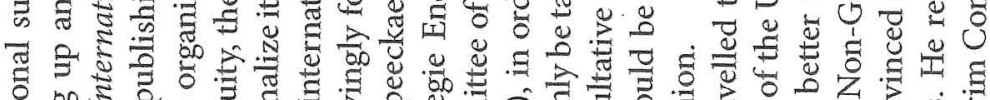
bo

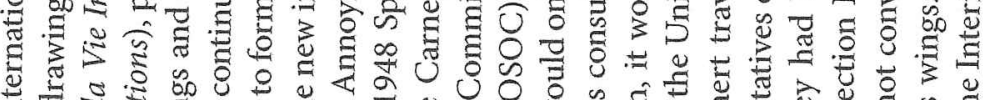

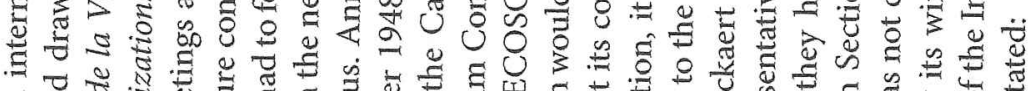

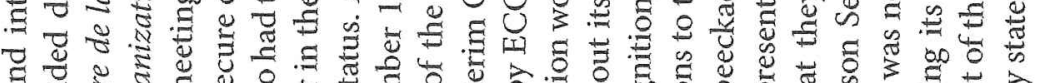

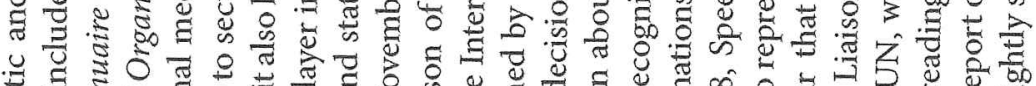

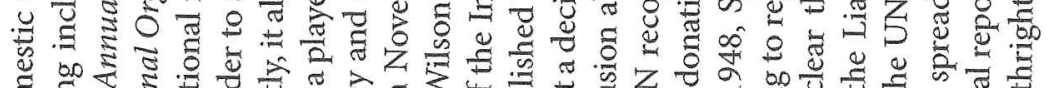

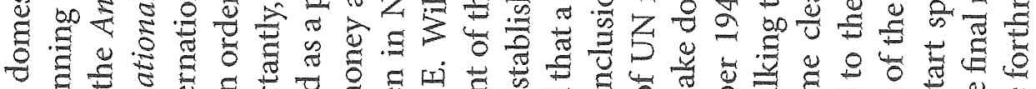

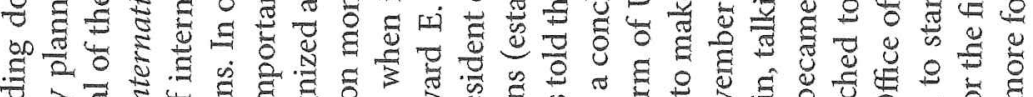

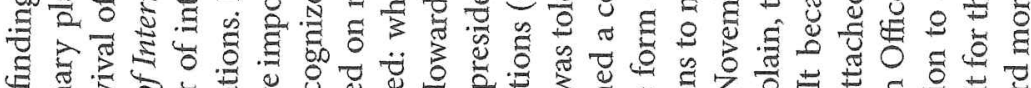

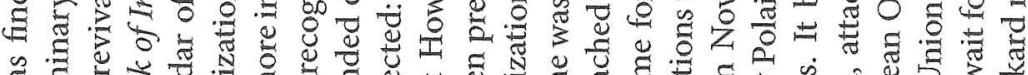

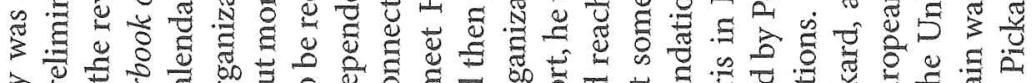

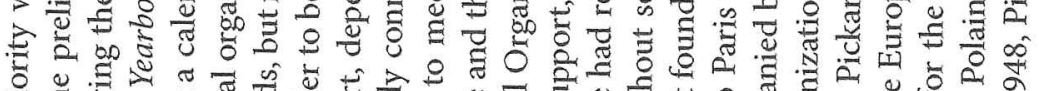

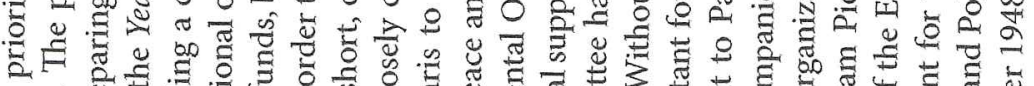

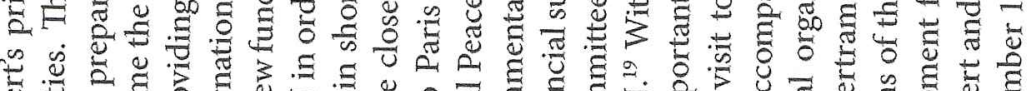

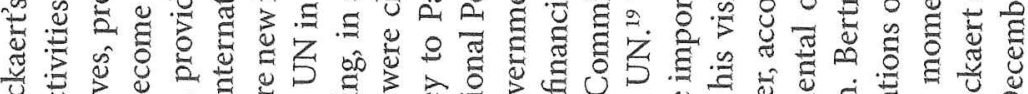

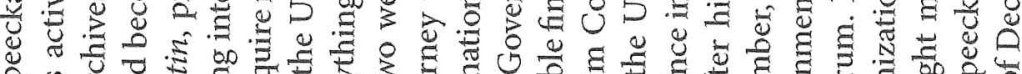
की

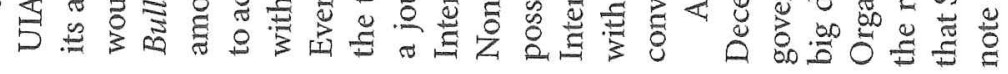

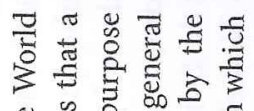

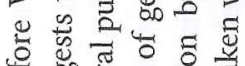

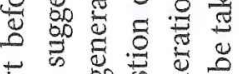

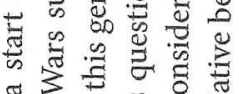

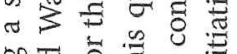

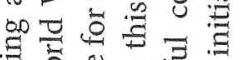

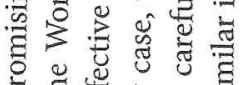

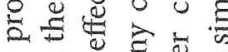

:

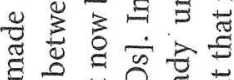

(

혈

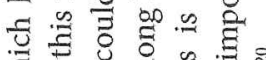

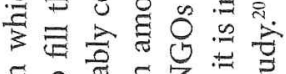

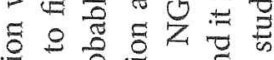

节产要

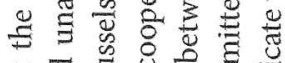

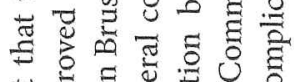

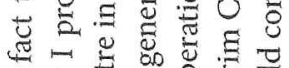

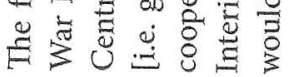

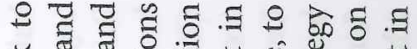

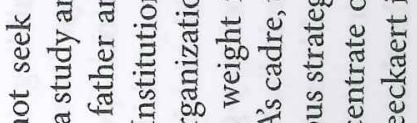
㐘

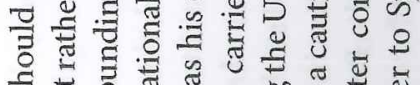
के 융

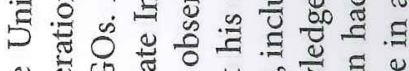
Ð

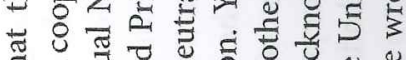

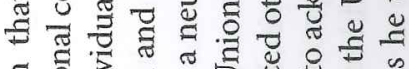
ธี

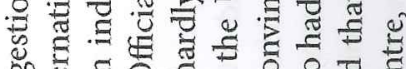

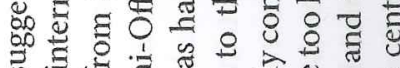
क.

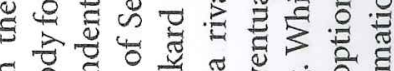

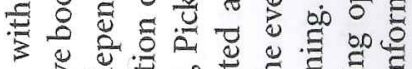
च ठ : ष \&

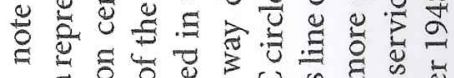
क ज

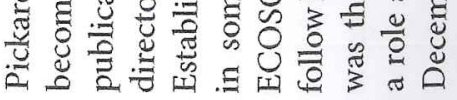




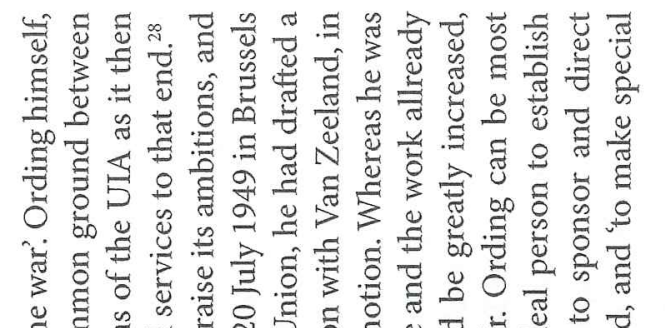

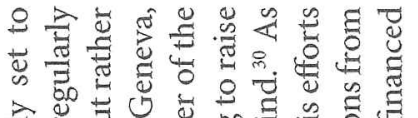

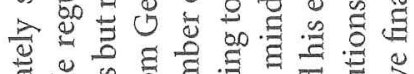

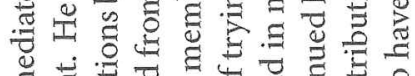

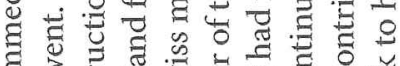

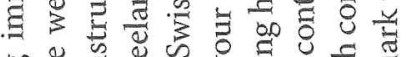

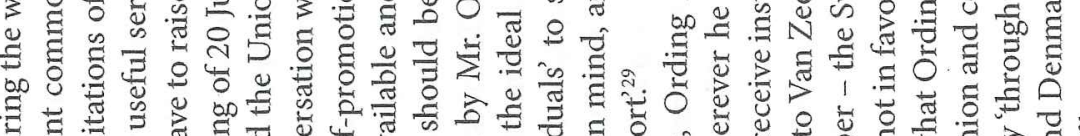

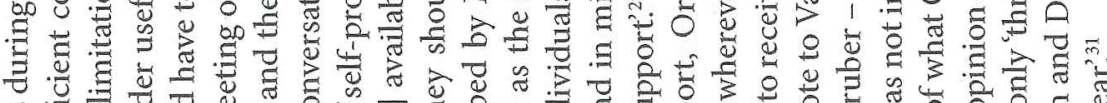

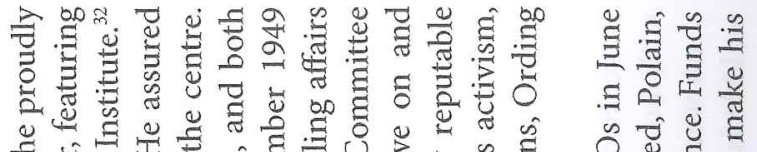

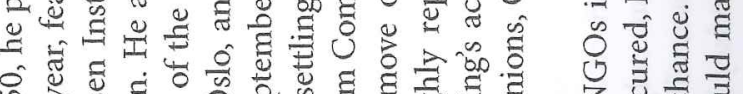
ڤ2

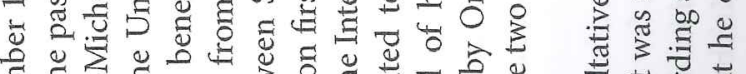

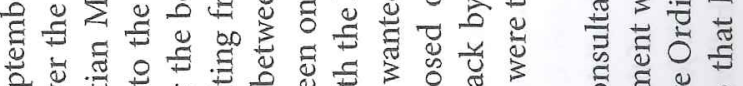

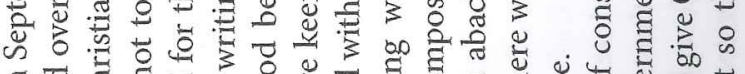

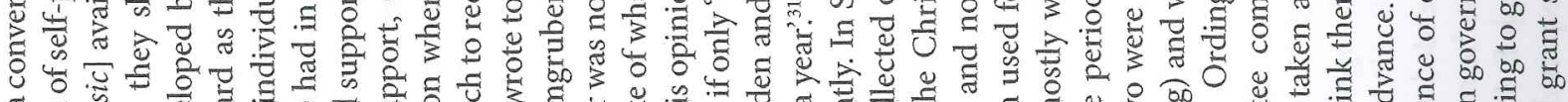

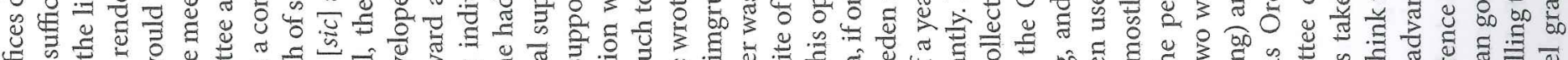

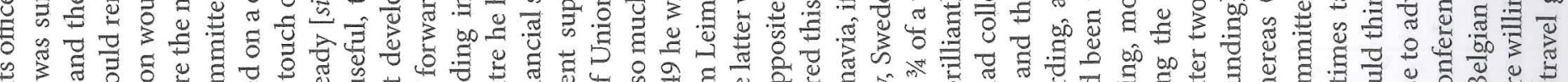

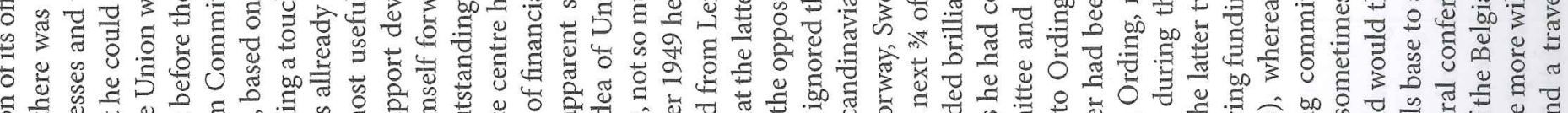

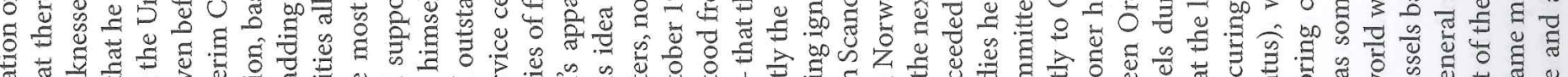

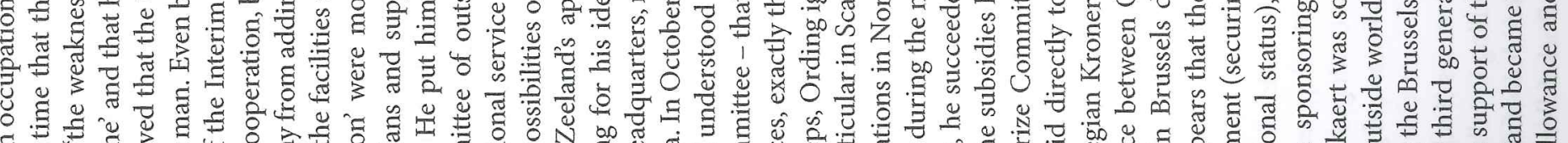

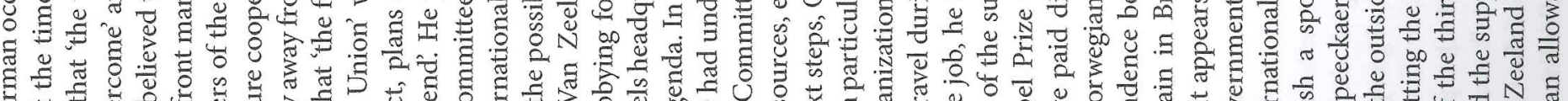

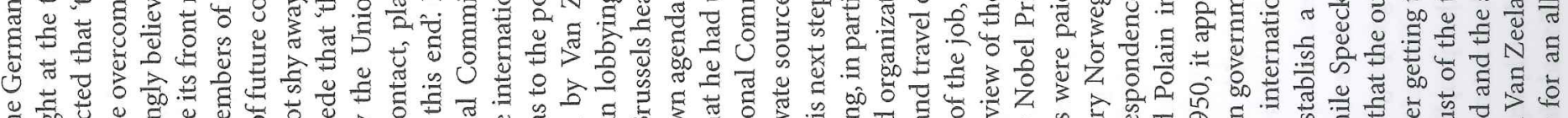

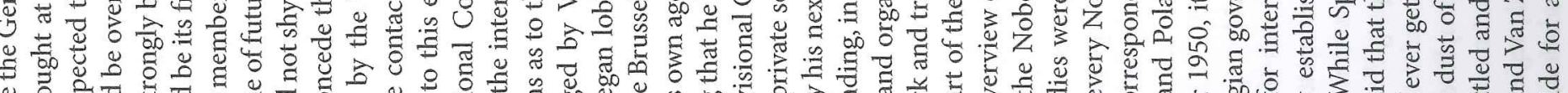

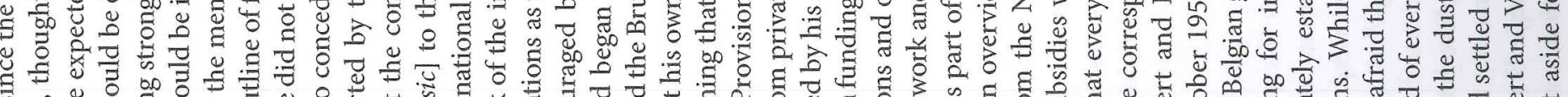

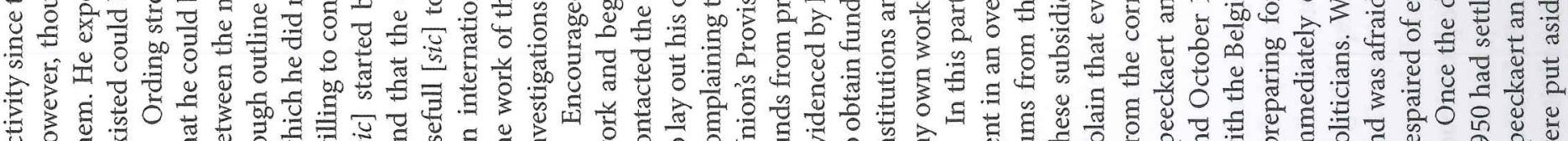

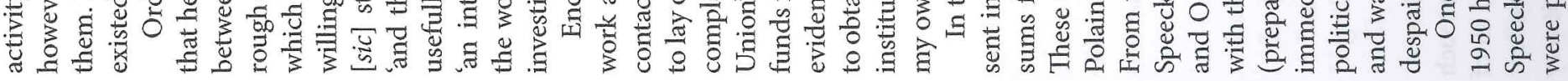

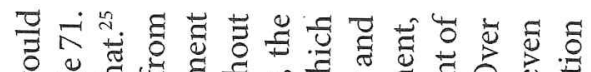

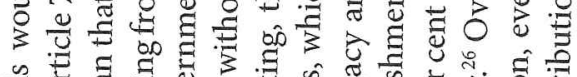

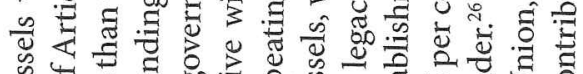
के क

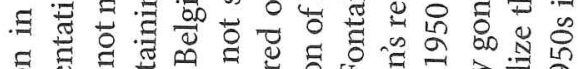

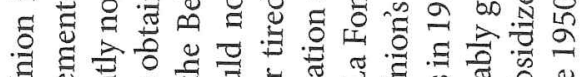

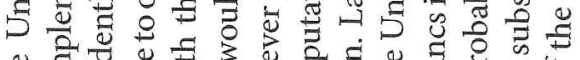

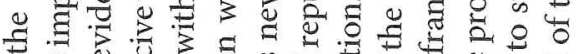

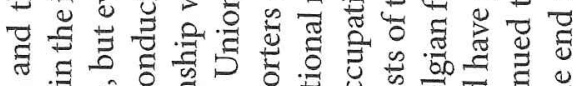
品

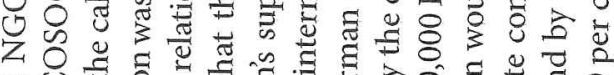

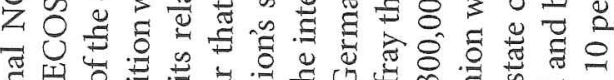

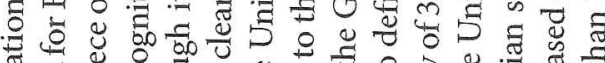

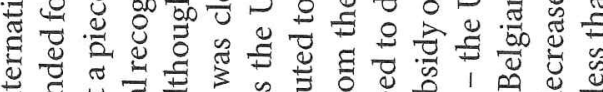

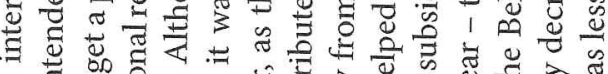

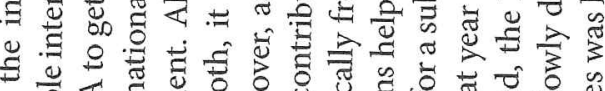
क

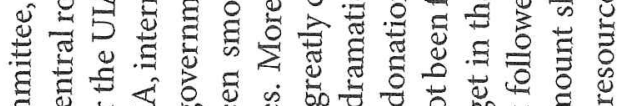
范志过

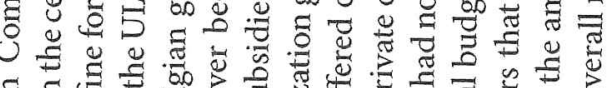
E

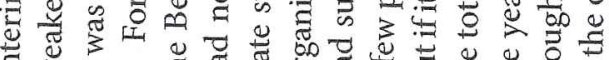

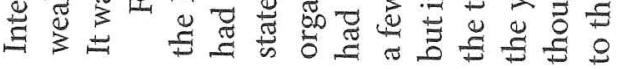

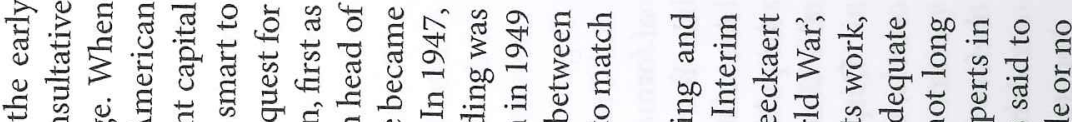
न

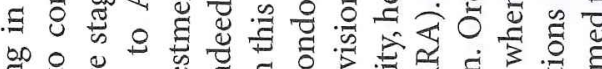

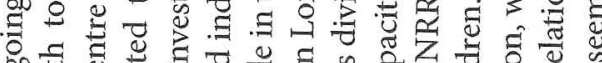
o

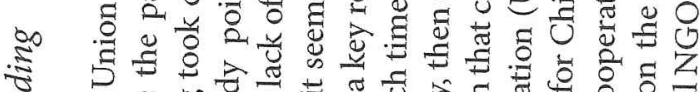

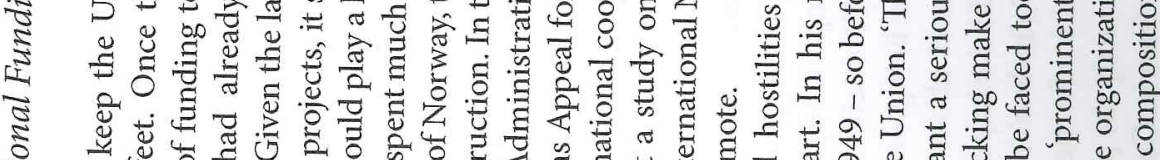

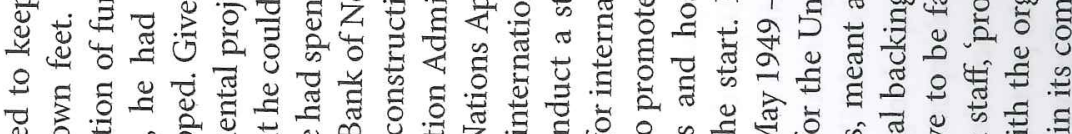

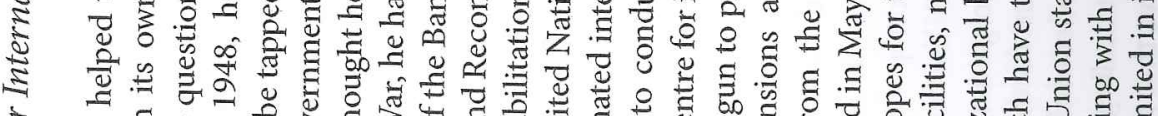

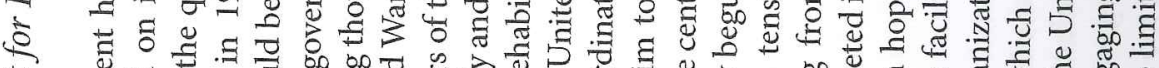
尊

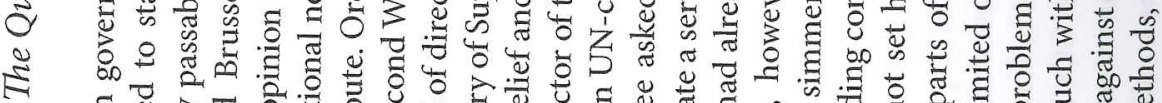

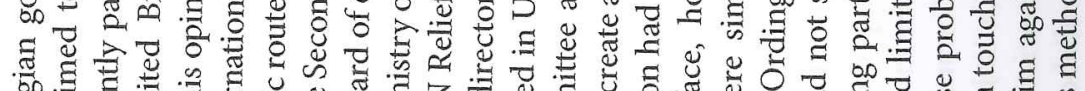

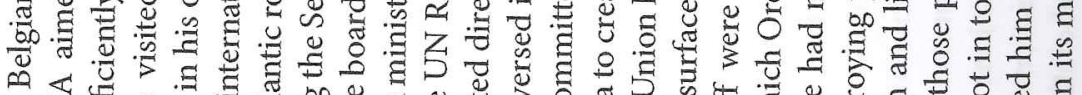

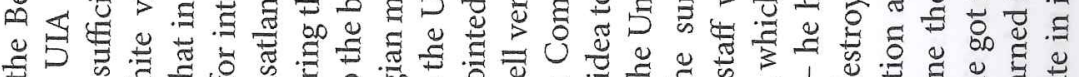

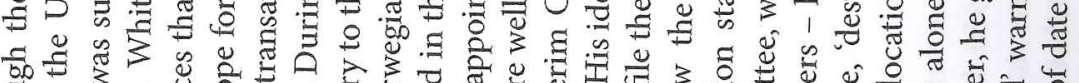

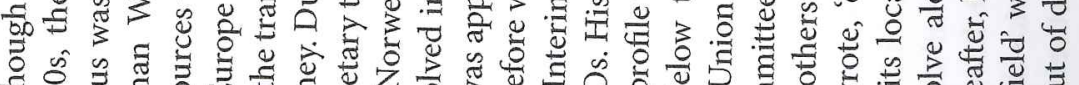

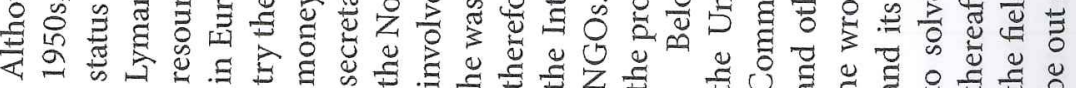



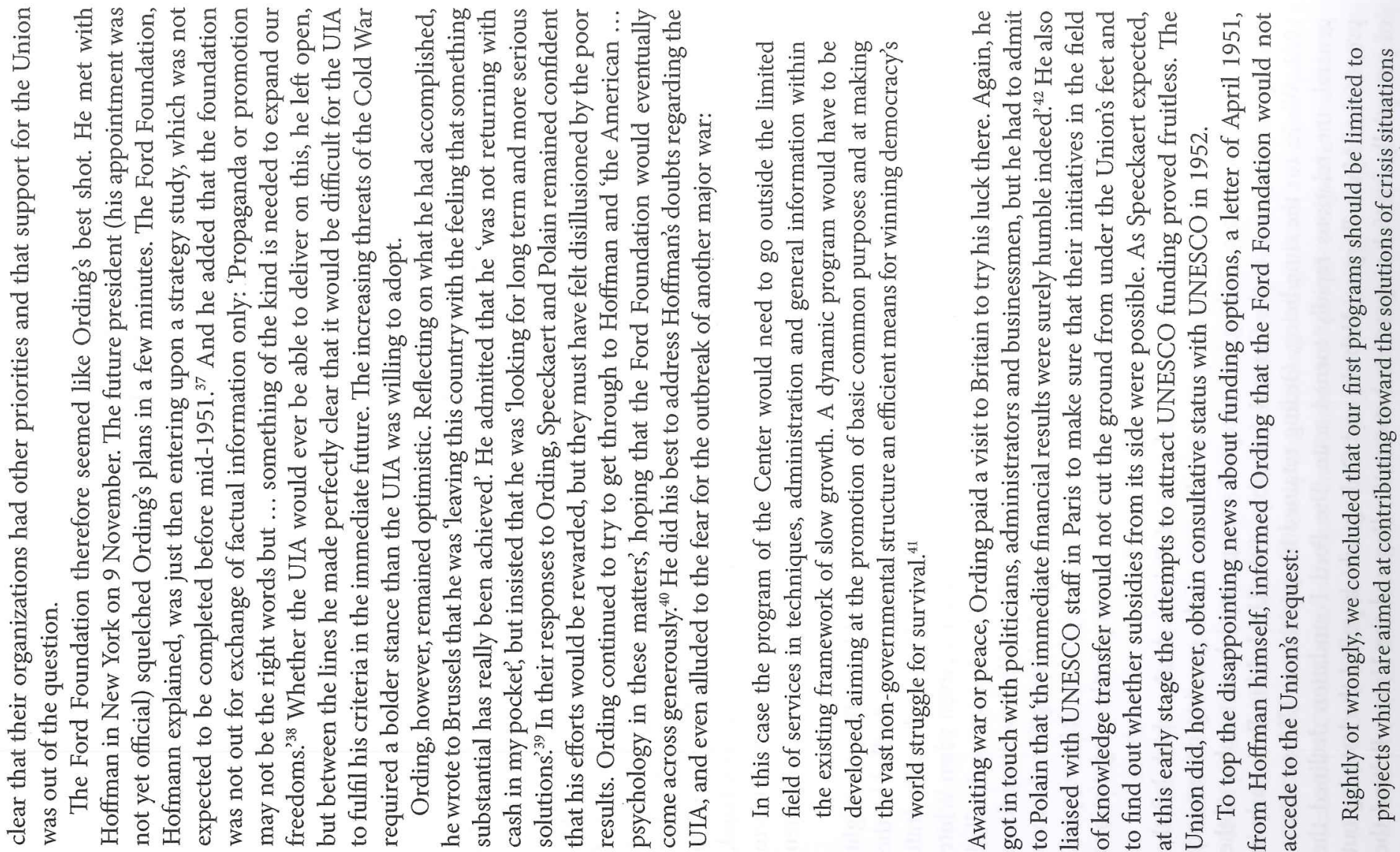

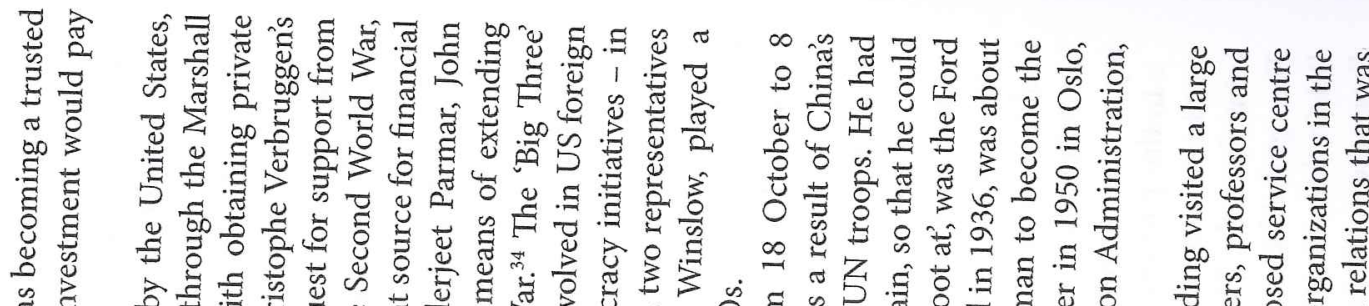

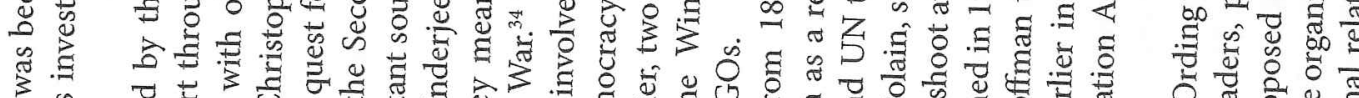

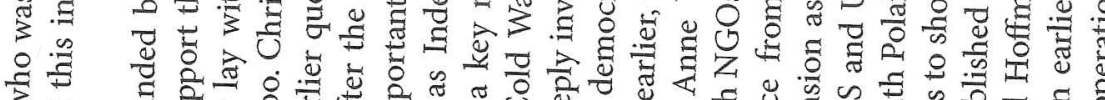

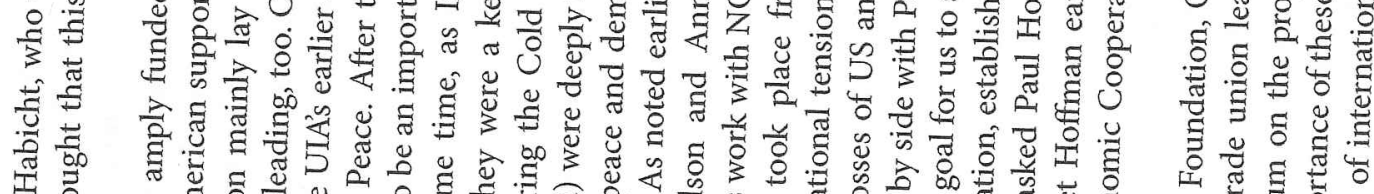

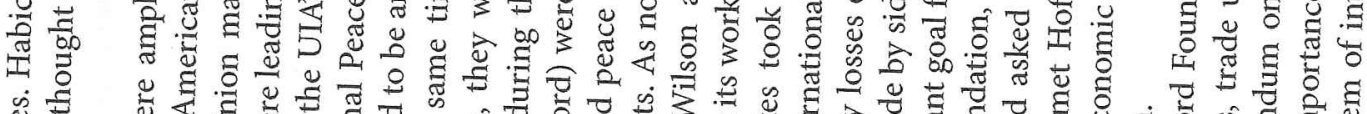

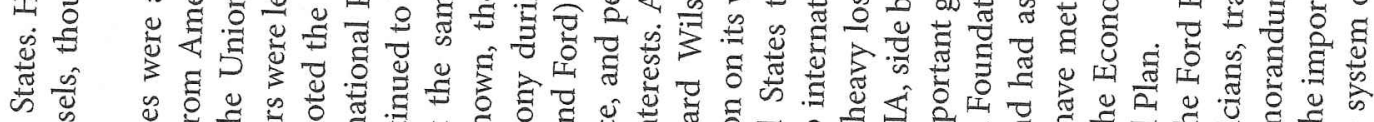

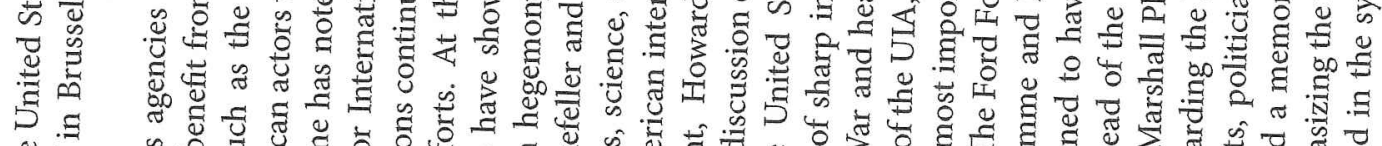

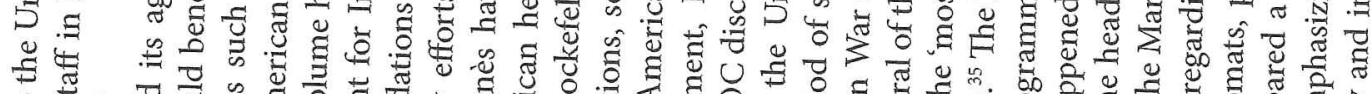

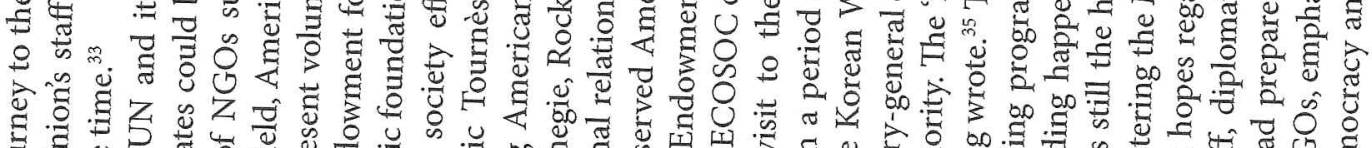

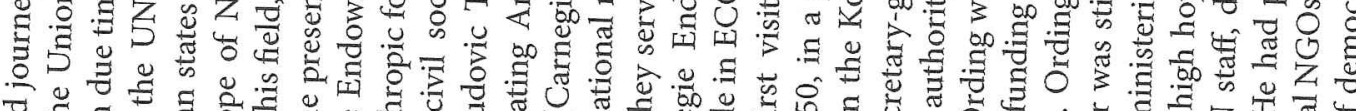

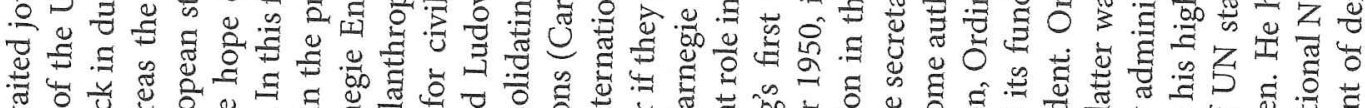

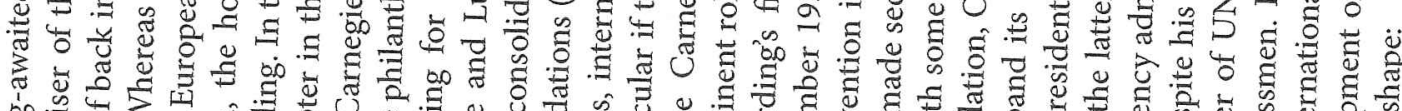

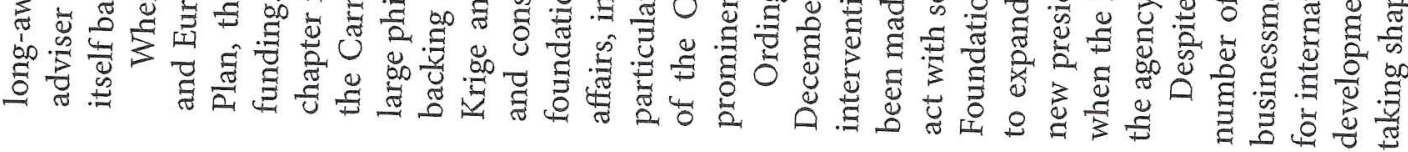

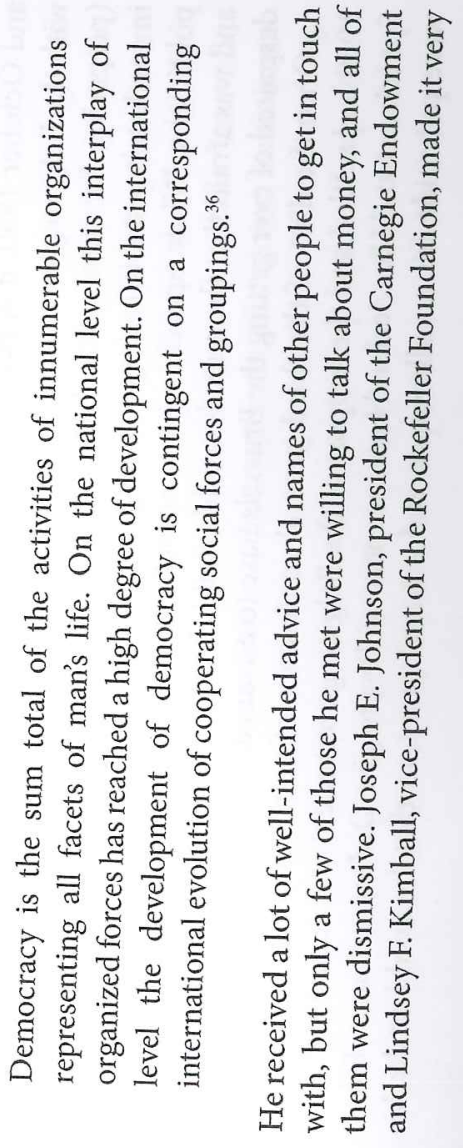




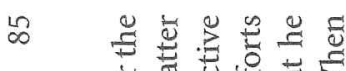

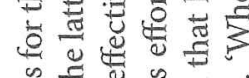

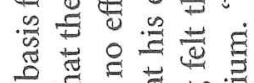

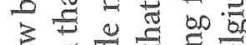

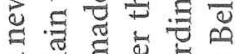

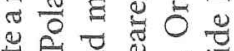

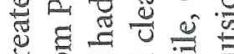

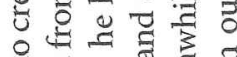
일

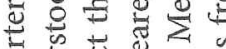

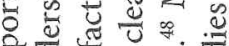

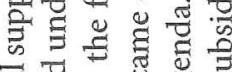

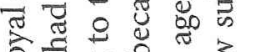

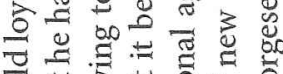
운

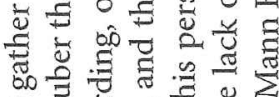

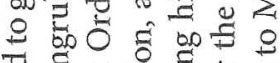
尊爱 5

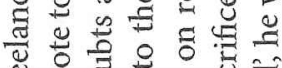
N

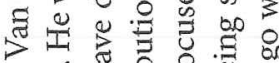

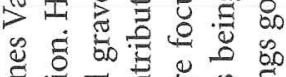

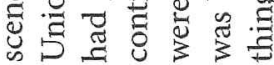

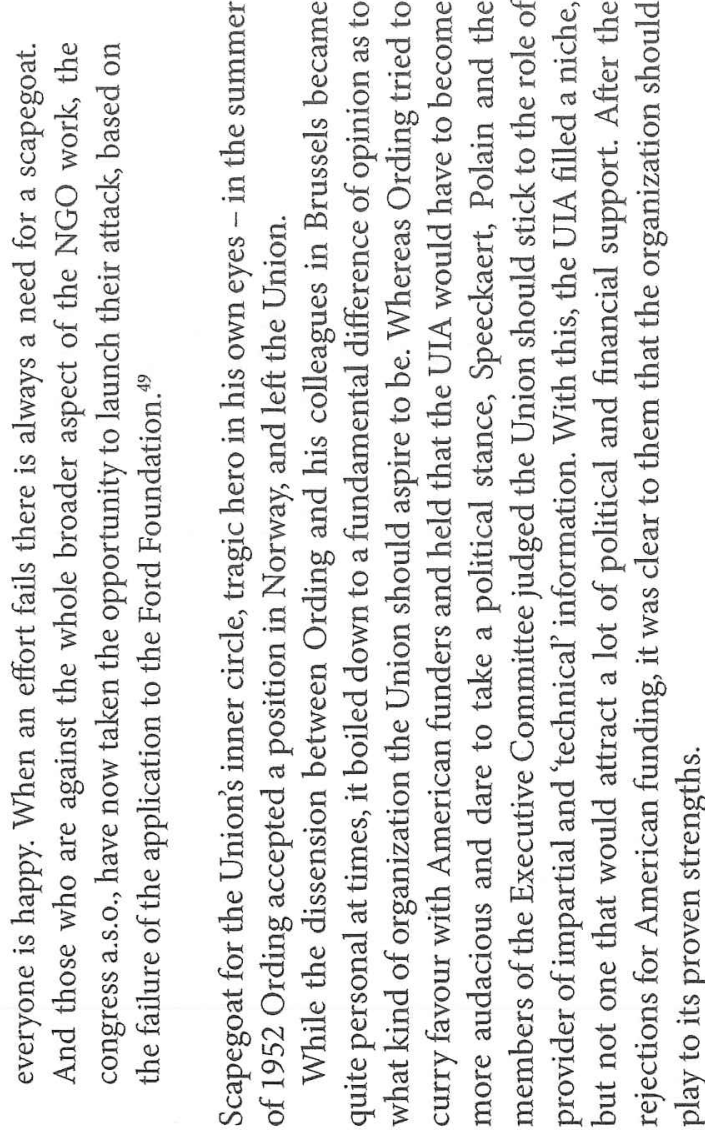

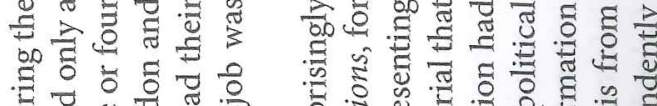

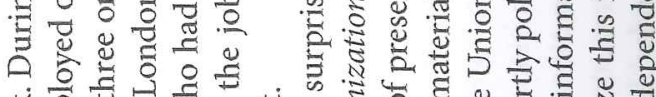
岛 等

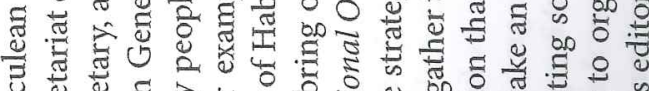

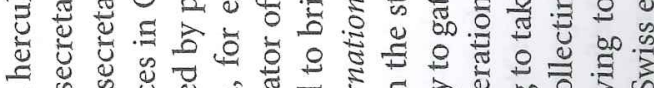

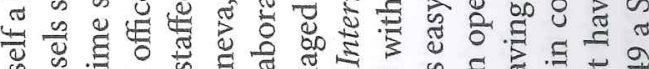

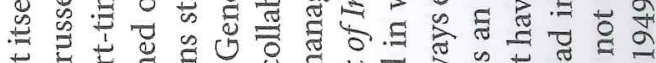

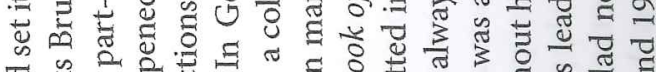

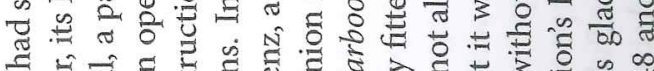

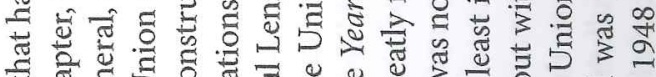

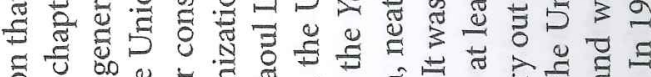

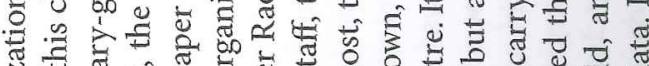

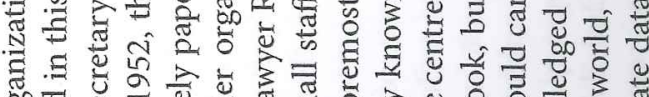

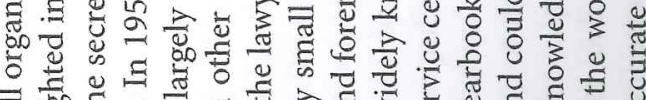

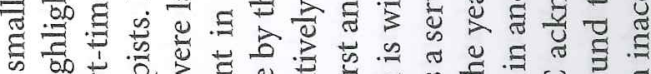
ob

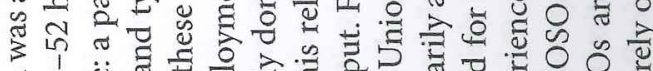

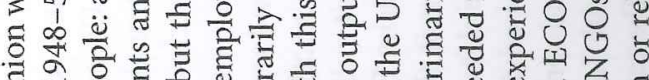
मे के

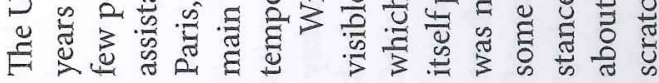

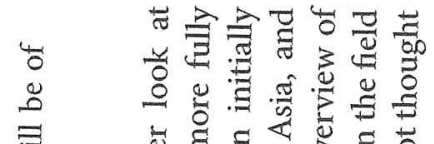

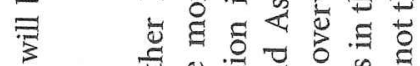

ง

률

芩

莽 00 击 .ี่

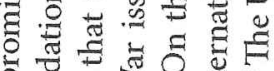

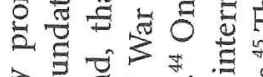

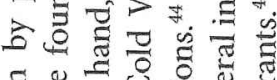

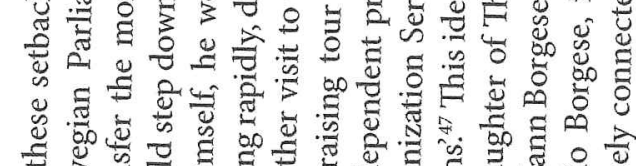
\%

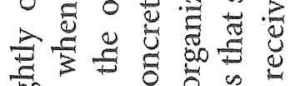

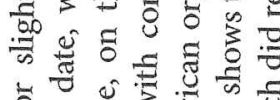

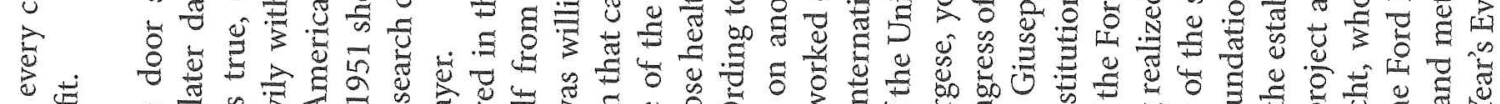

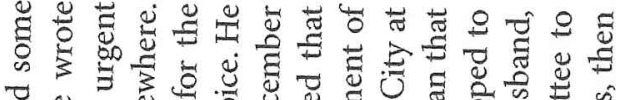

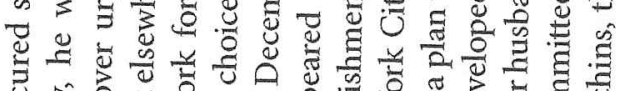

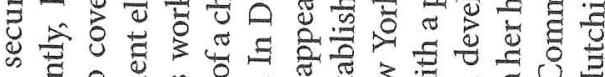

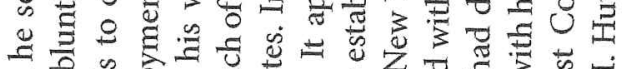
चี ญ

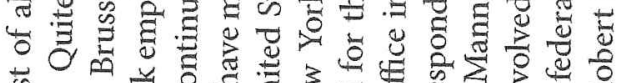
帝 is บี

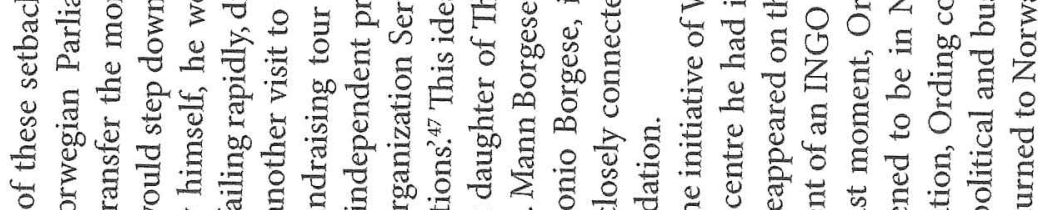

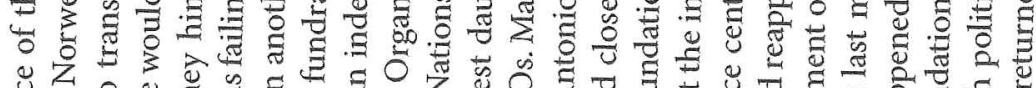

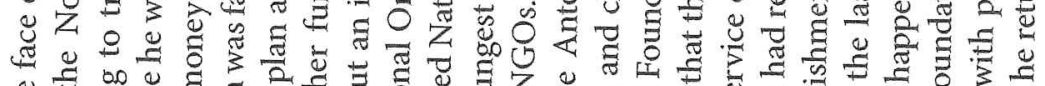

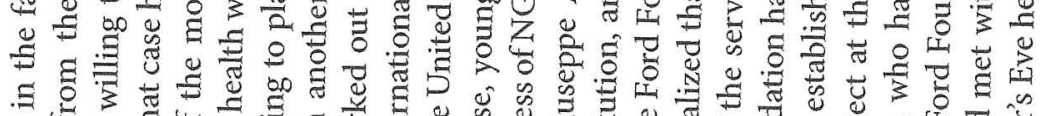
Ð

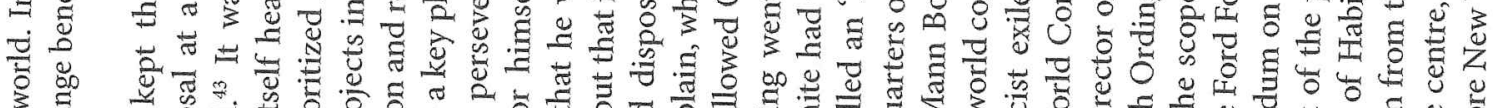

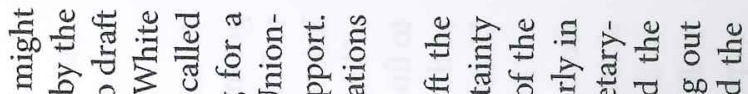

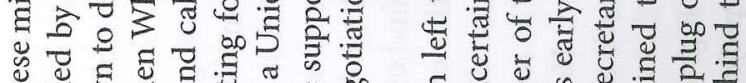
ơ

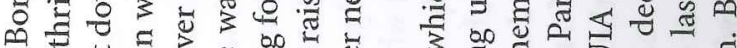

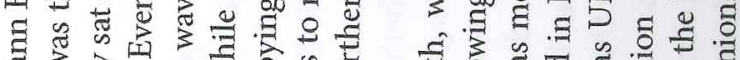

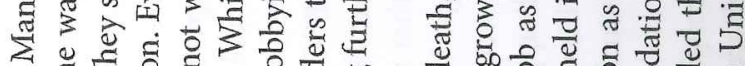

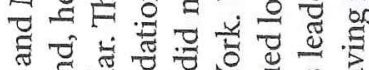

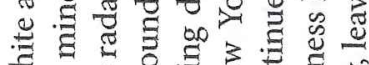

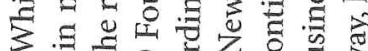

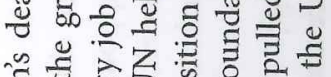

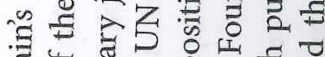

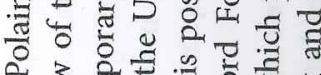

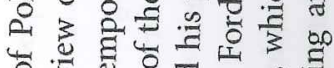
पे

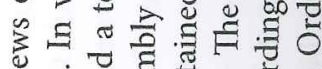

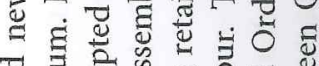

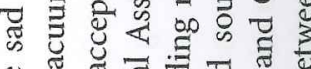
\& ఫ记 ¿

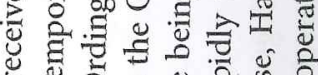
¿ 0 ठ ह.

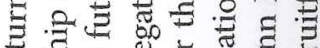

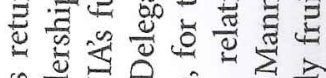
ङ ヨ

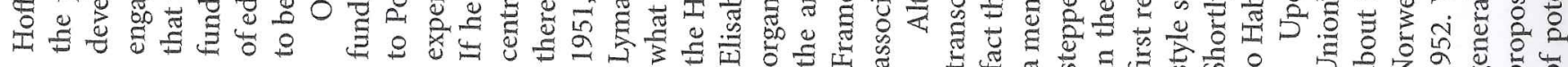




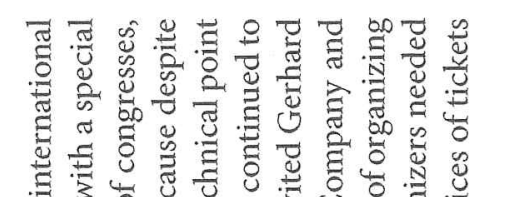

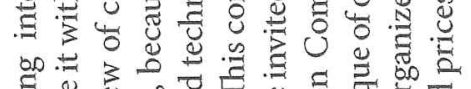

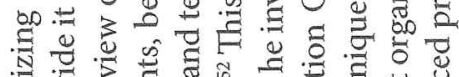

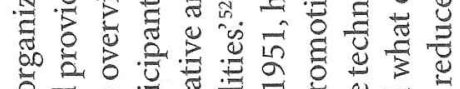

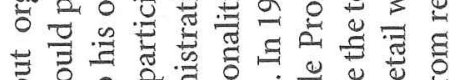

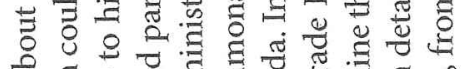

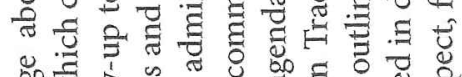

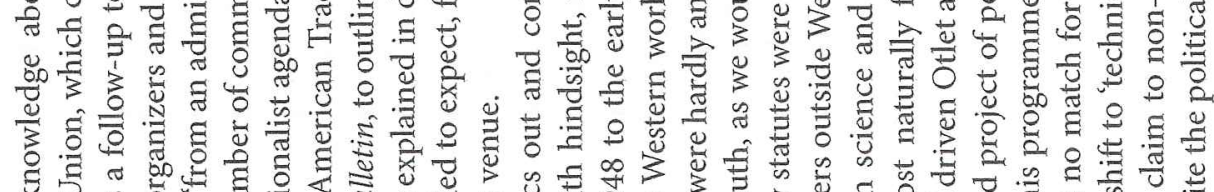

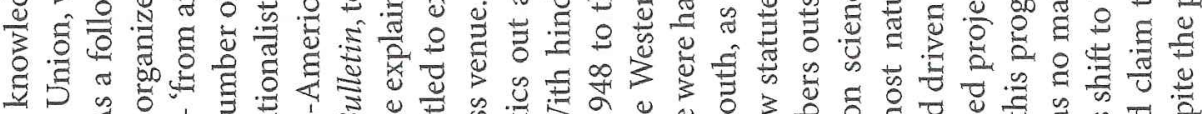

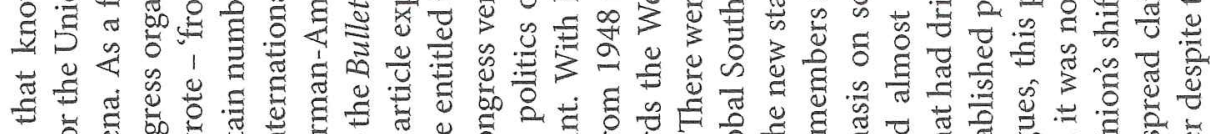
Int

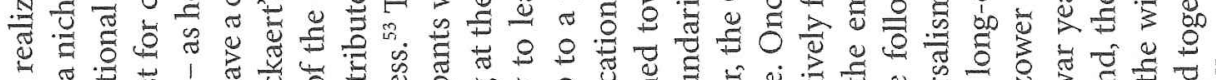

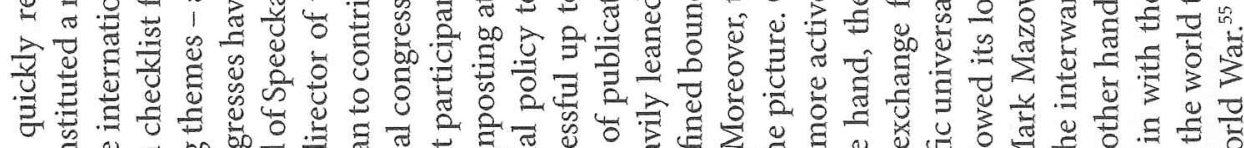

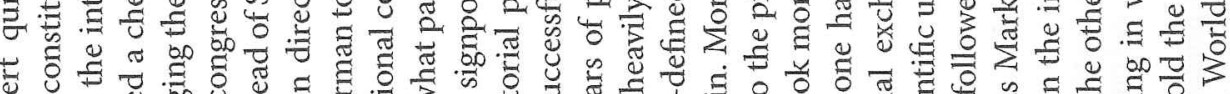

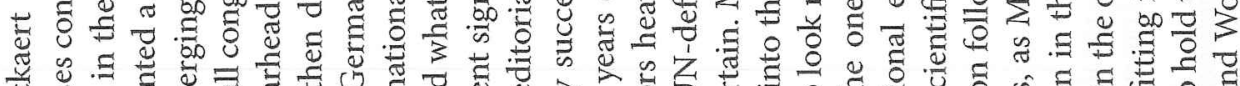

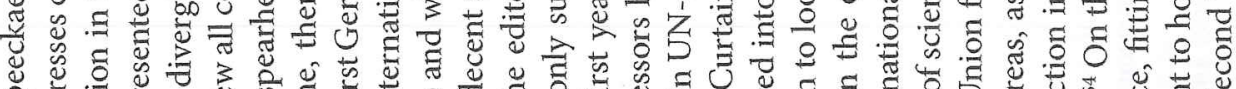

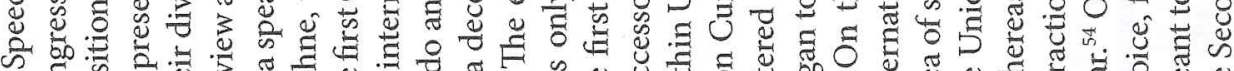

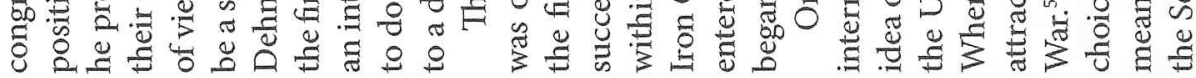

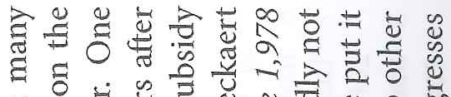

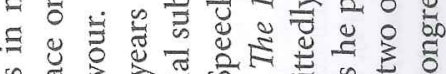

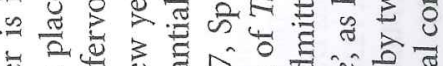

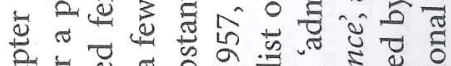
क्षै

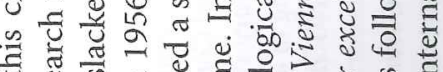

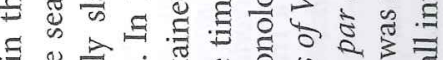

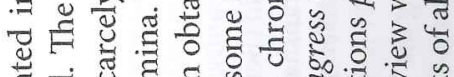

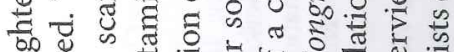

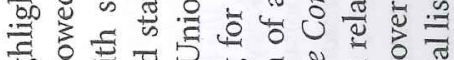

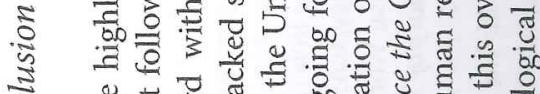

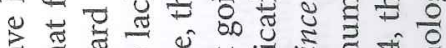

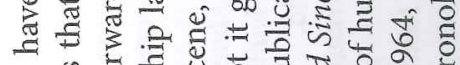

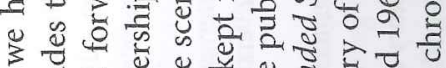

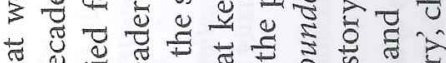
$\cong$ 는 กิ 1

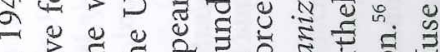

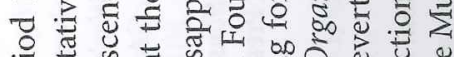
纯

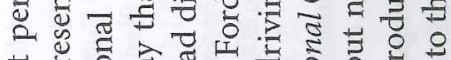

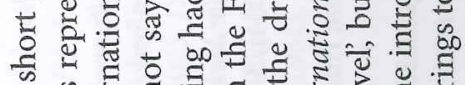

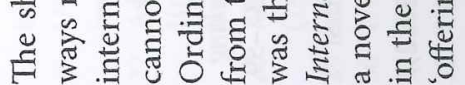

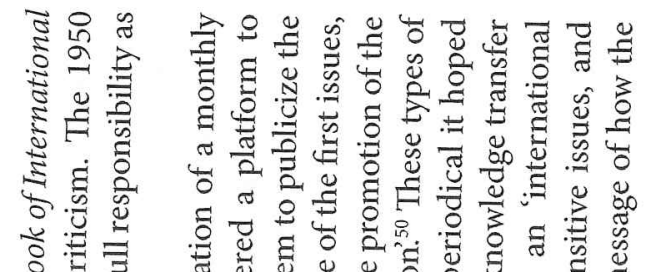

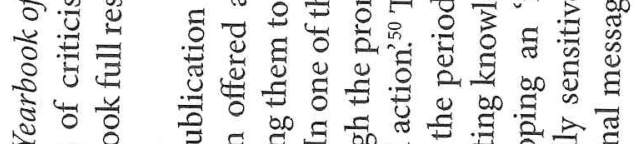

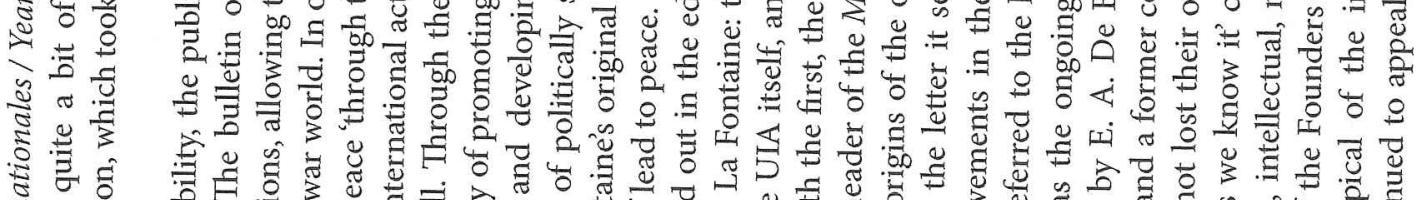

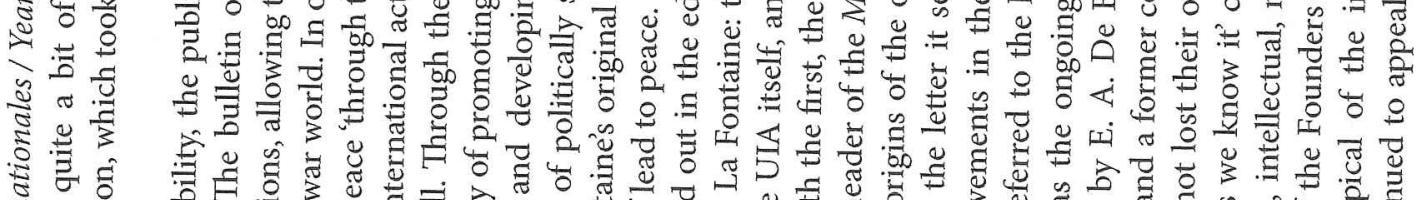

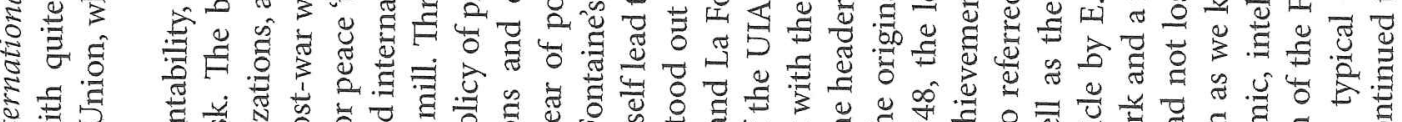

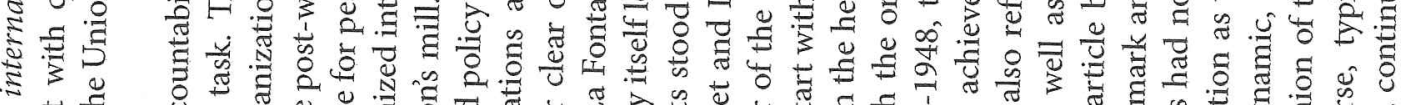

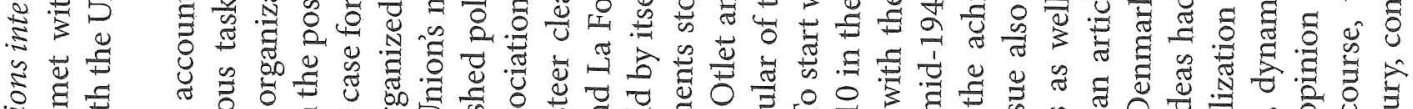

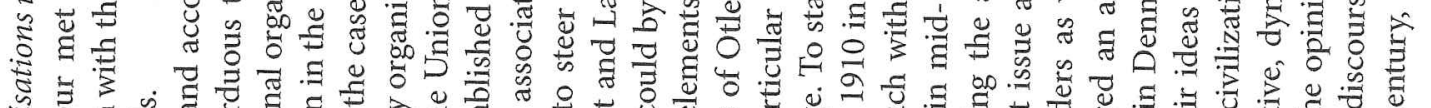

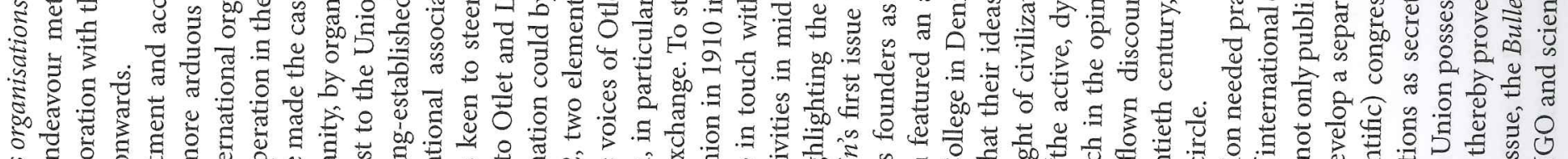

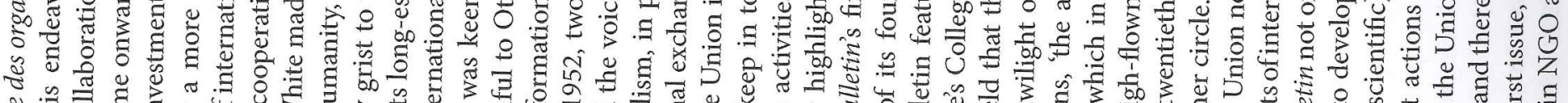
Mㄴ.

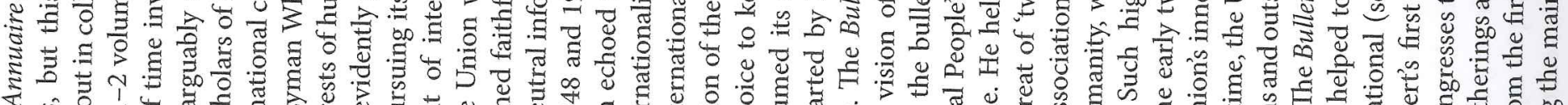

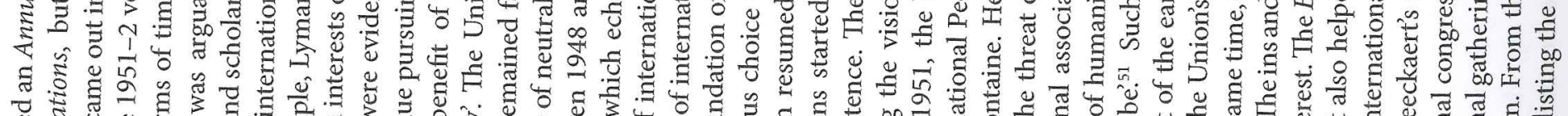
Mํ.

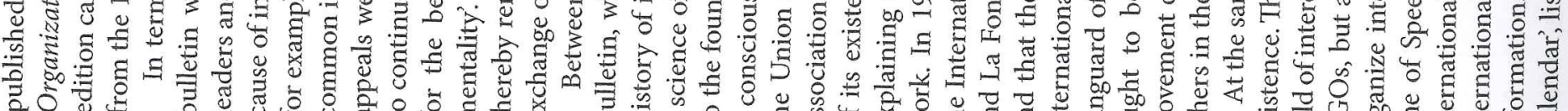

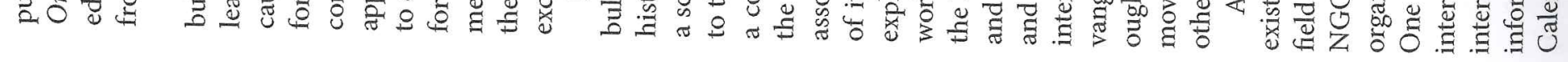


$\infty$

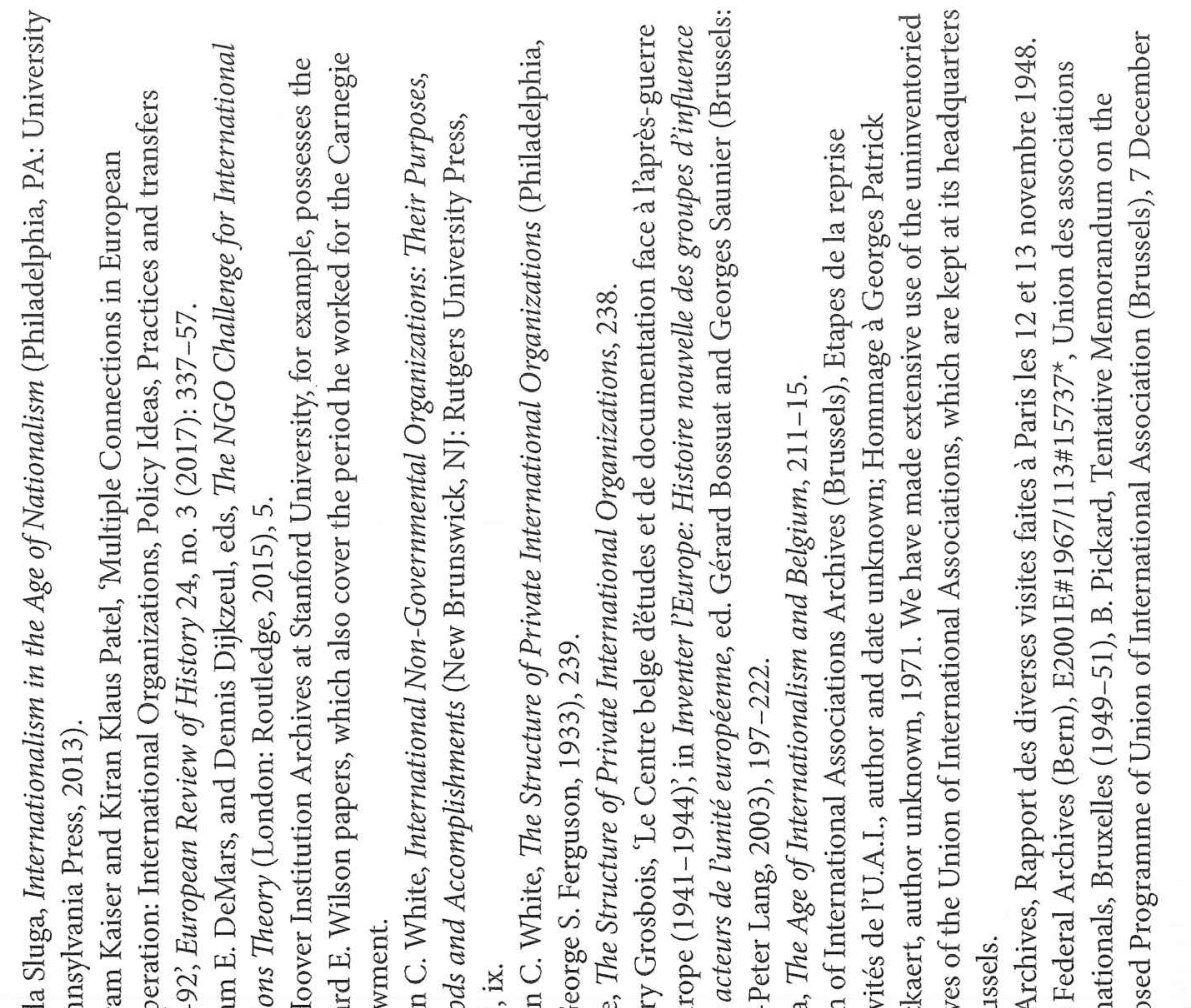

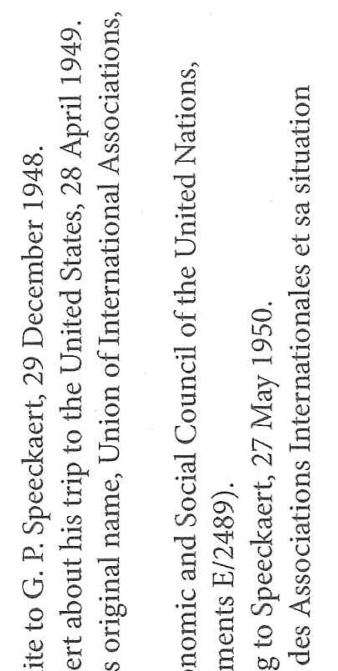

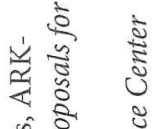

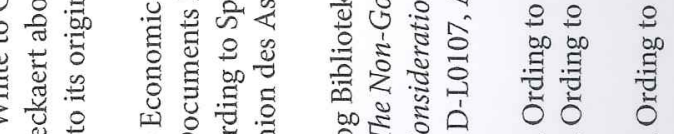
उ范范

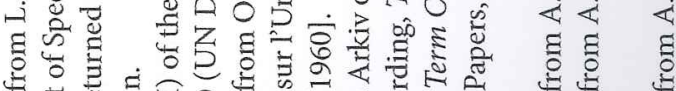

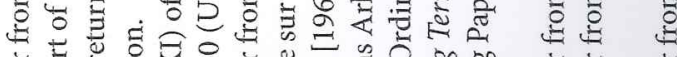

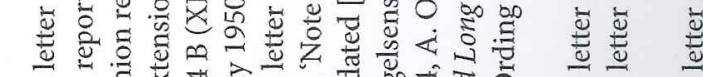
की

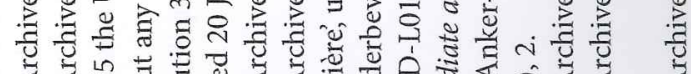

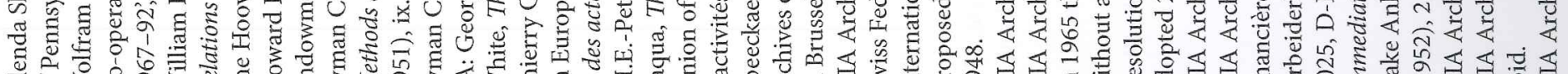

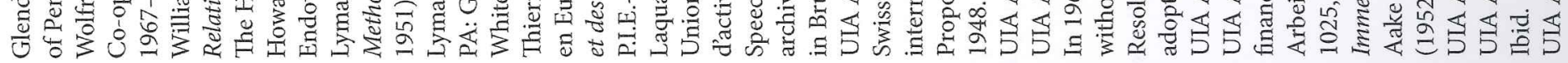

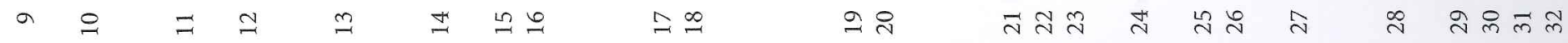

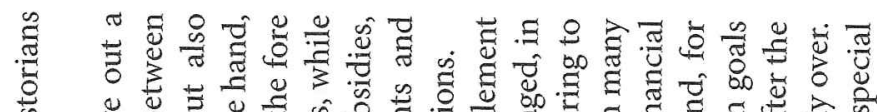

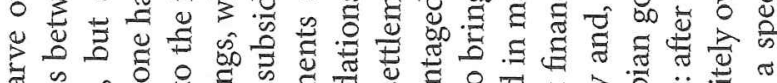

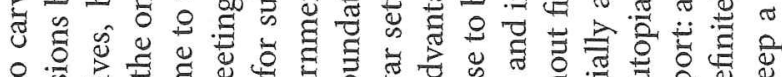

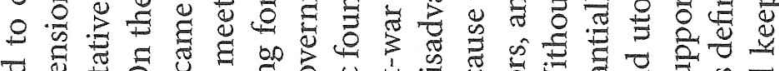

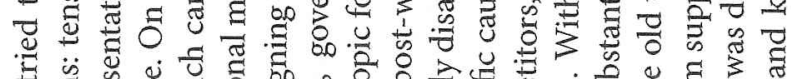

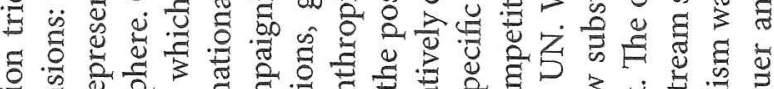

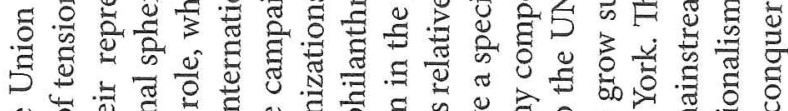

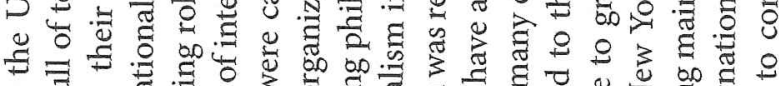

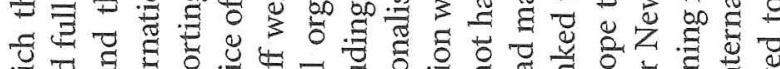
3

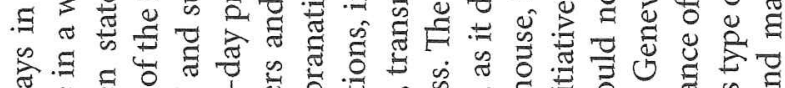

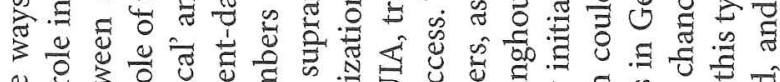

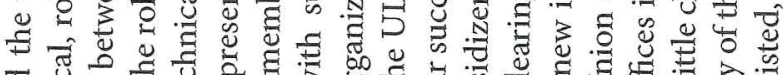

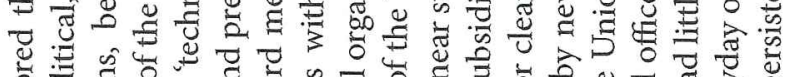

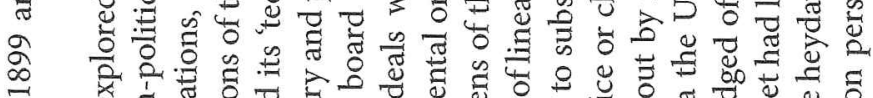
I

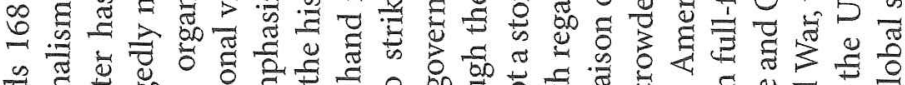

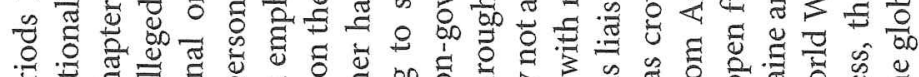

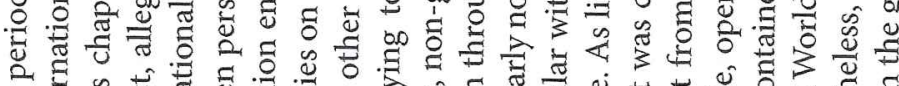

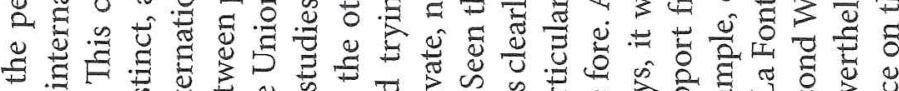

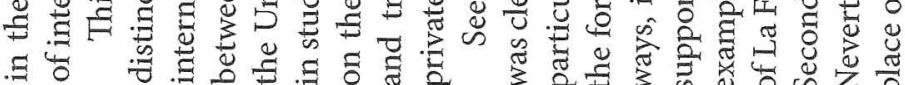

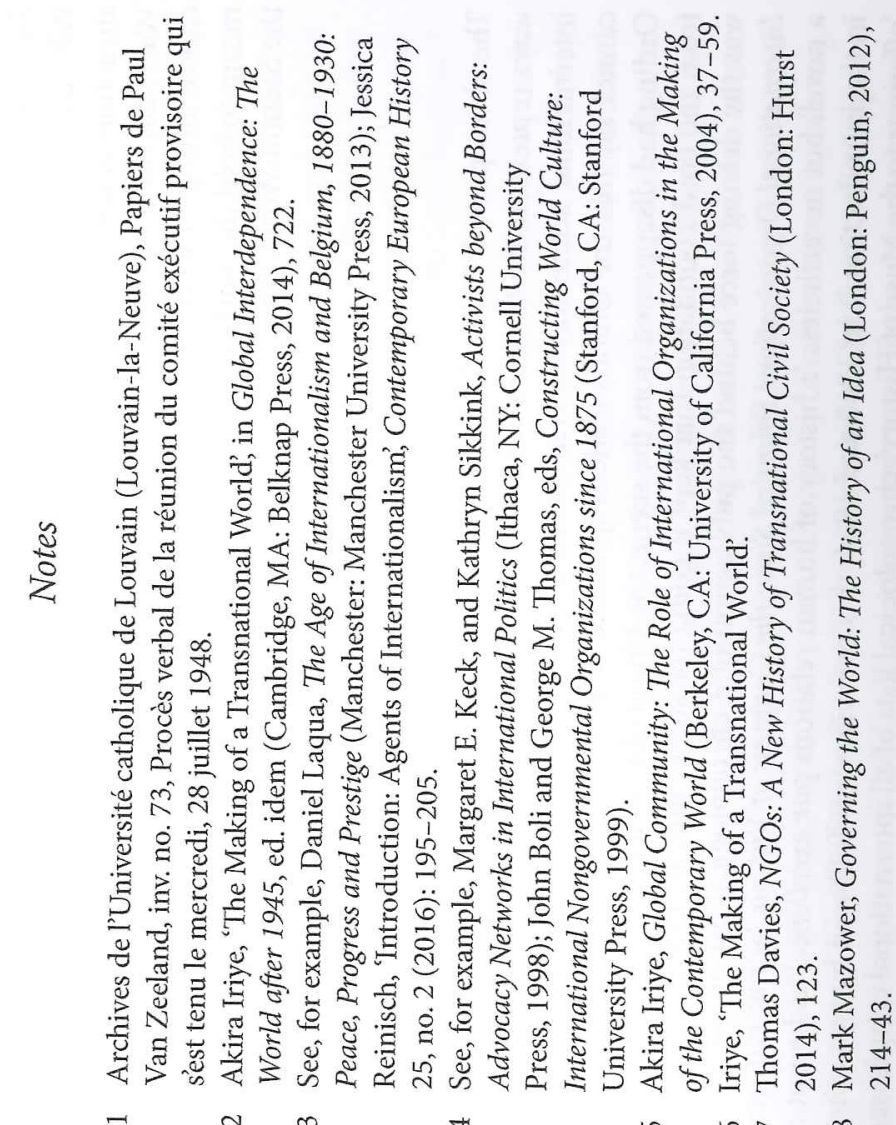




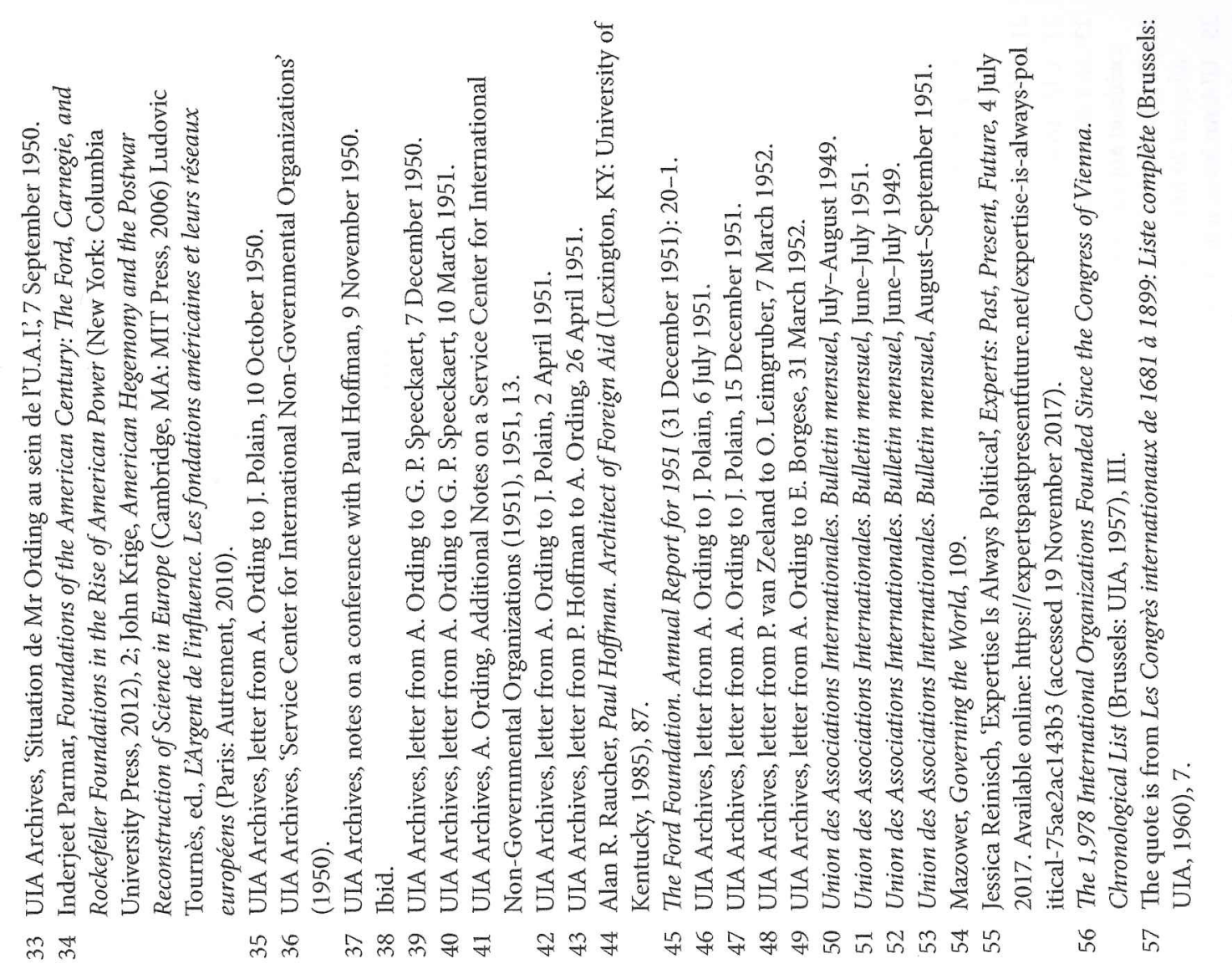

